\title{
The Prospect of Combining a Point Absorber Wave Energy Converter with a Floating Offshore Wind Turbine
}

\author{
David M. Skene *(D), Nataliia Sergiienko, Boyin Ding and Benjamin Cazzolato \\ School of Mechanical Engineering, The University of Adelaide, Adelaide 5005, Australia; \\ nataliia.sergiienko@adelaide.edu.au (N.S.); boyin.ding@adelaide.edu.au (B.D.); \\ benjamin.cazzolato@adelaide.edu.au (B.C.) \\ * Correspondence: david.skene@dst.defence.gov.au
}

Citation: Skene, D.M.; Sergiienko, N.; Ding, B.; Cazzolato, B. The Prospect of Combining a Point Absorber Wave Energy Converter with a Floating Offshore Wind Turbine. Energies 2021, 14, 7385. https://doi.org/10.3390/ en14217385

Academic Editors: Eugen Rusu and Mohamed Benbouzid

Received: 15 September 2021

Accepted: 28 October 2021

Published: 5 November 2021

Publisher's Note: MDPI stays neutral with regard to jurisdictional claims in published maps and institutional affiliations.

Copyright: (c) 2021 by the authors. Licensee MDPI, Basel, Switzerland. This article is an open access article distributed under the terms and conditions of the Creative Commons Attribution (CC BY) license (https:/ / creativecommons.org/licenses/by/ $4.0 /)$.

\begin{abstract}
With recent advances in offshore floating wind and wave energy technology, questions have emerged as to whether the two technologies can be combined to reduce their overall levelised cost of energy. In this paper, the potential for combining a floating offshore wind turbine to a point absorbing wave energy converter is investigated. The focus of the investigation is how much power might be produced by a combined floating wind and wave energy converter system, and the resultant changes in motion of the floating wind platform. A model for the combined wave and wind system is developed which uses the standardised NREL OC3 $5 \mathrm{MW}$ spar type wind turbine and a cylindrical buoyant actuator (BA), which is attached to the spar via a generic wave power take-off system (modelled as a spring-damper system). Modelling is conducted in the frequency domain and the tests span a wide range of parameters, such as wave conditions, BA sizes, and power take-off coupling arrangements. It is found that the optimal (with respect to power production) BA size is a draft and radius of approximately $14 \mathrm{~m}$. It is found that this BA can theoretically produce power in the range of 0.3 to $0.5 \mathrm{MW}$ for waves with a significant wave height of $2 \mathrm{~m}$, and has the potential to produce power greater or near to $1 \mathrm{MW}$ for waves with a significant wave height of at least $3 \mathrm{~m}$. However, it is also found that, in terms of the relative capture width, significantly smaller BAs are optimal, and that these smaller BA sizes less significantly alter the motion of the floating wind platform.
\end{abstract}

Keywords: wave energy; offshore floating wind energy; wave-structure interactions

\section{Introduction}

Site studies find that most viable offshore wind energy sites have promising amounts of wave energy [1,2]. Therefore, with recent advances in wave and offshore wind energy technology, questions have arisen as to whether the two technologies can be combined in a manner that utilises their synergies. In principle, the benefits of this combination include legislative synergies, surveying synergies, enhanced energy yield, smoothed power output, common infrastructure, shared logistics, and reduced intermittency [1]. These benefits have the potential to lower the levelised cost of energy (LCOE) of both technologies, which for offshore wind is approximately double that of its onshore counterparts [3], and is difficult to measure for wave energy as it has not yet matured to a commercial scale [4].

It is necessary to consider the current state of wind and offshore wave energy technology in order to consider how a combined system might be realised. The design of wind energy generation systems appears to have converged to a three-blade horizontal axis turbine mounted on a cylindrical tower. At present, these systems generate power typically in the order of megawatts [5] and their design is well established. As onshore wind technology has matured, there has been a concerted effort to adapt the systems to offshore sites. A significant issue in moving wind turbines offshore is how the fixed connection to the ground is adapted to a seabed connection [6]. The current consensus is that, for depths of less than approximately $60 \mathrm{~m}$, a design where the tower is fixed to the seabed is economically viable, whereas for depths greater than approximately $60 \mathrm{~m}$, floating 
platforms are more economically competitive [6]. Of these floating platforms there appears to be three main design varieties. The first is a tensioned leg platform, where the platform is stabilised through the tension of the mooring tethers [7]. The second is a semi-submersible, where the platform is stabilised through a floating but partially submerged structure with a large water-plane volume moment of inertia [8]. The third is a spar type structure where stability is provided through the platform having a centre of mass well below the water's surface [9]. All of these platform types have their own design eccentricities; however, their unifying purpose is to suppress the motion (particularly pitch) of the wind turbine tower they are connected to [10].

In comparison to wind energy, wave energy is a relatively immature technology. At present, there exists a large number of prototype designs under the various categories of point absorber/oscillating bodies, overtopping devices, oscillating water columns, and others $[4,11-13]$. While there have been significant advancements in the modelling and production of these devices [14], the technology has yet to reach the level of maturity where they are commercially viable, and the specific 'winning' design (akin to the three-turbine wind turbines) has yet to be identified [15].

At present, there exists three distinct variations on how wind and wave energy can be combined [1]. The first is co-location, but with separate wind and WEC deployment areas wherein the wind and wave energy systems are placed far enough apart that they effectively act in isolation but share a common connection to the power grid. The second is co-location within the same area. This requires the wind and wave devices be inter-spread amongst each other. This combination offers the same LCOE benefits as the devices acting in isolation, but also potential for added LCOE benefits related to the scattering of the waves such that they enhance wave energy power generation while reducing the wave forces on the wind turbine's structures. The third is a hybrid system, which combines the wind and wave energy converter in a shared platform. This offers the same benefits as the other options but also has potential LCOE benefits with respect to shared foundations and structures. Of these hybrid systems, there exists two separate classes-those for fixed offshore wind turbines and those for floating offshore wind turbines. The hybrid system for a fixed offshore wind turbine effectively replaces all or some of the WEC's seabed connections with connections to the wind turbine's tower. The hybrid system for a floating offshore wind turbine also replaces these seabed connections with connections to the wind turbine; however, this introduces a distinctive change in behaviour where the WEC is now connected to a dynamic body. This paper investigates this kind of floating offshore wind turbine hybrid system.

A number of prototype designs have been proposed with respect to the design of a floating wind and wave hybrid platform. These include designs such as W2Power [16], Poseidon37/80 [1], WindWaveFloat [13], DeepCwind-Wavestar-Combined [17], and others $[18,19]$. These designs can differ significantly. For instance, the floating hybrid platform can have one or multiple wind turbines; can be of a spar, barge, or semi-submersible platform variety; can use WECs of the point absorber, overturning, or oscillating water column variety; can use multiple or single WEC devices; for the point absorber, WEC variation can have heaving, pitching, or multiple degree of freedom attachments; and many other minor design eccentricities. Nonetheless, these devices primarily tend towards having WECs of the point absorber variety, and the research work focuses on the power production the WECs can achieve as well as the resultant dynamics of the hybrid platform [1,17,19-21]. As is expected in the early prototyping phase, the research on these floating hybrid platforms focuses on the design and optimisation of a particular specific design rather than developing a more general perspective on the consequences of attaching a point absorber to a floating wind platform.

Accordingly, the work in this manuscript has been undertaken in order to develop a more general study on the potential for combining a floating wind turbine with a point absorbing wave energy converter. Within, this paper investigates the potential for attaching a generalised point absorbing wave energy converter to an existing floating wind platform 
design. A point absorber WEC is considered because of its popularity amongst wave energy converter research, breadth of possibilities when integrating its structure with a floating offshore wind turbine, and the number of prototype designs that use point absorbers connected to offshore wind turbines. The point absorber is modelled as a generic floating cylindrical buoyant actuator (BA) and a wide range of BA drafts and radii are considered. The NREL OC3 $5 \mathrm{MW}$ spare type floating wind platform [9] is used to model the floating wind turbine. This design is used because it is an established design, its specifications are freely available, and its spar structure allows for a wide range of potential coupling configurations to the point absorber. A specific design for the power take-off (PTO) system (i.e., wave energy conversion system) between devices is not proposed. Instead, a wide range of theoretically feasible couplings are explored as an abstracted spring and damper system to capture the kind of point absorber connections that might be realisable in the real world. Modelling is conducted in two-dimensions (although three-dimensional wave scattering effects are incorporated) and in the frequency domain as its low computational cost allows a wide range of design parameters to be considered. The environmental conditions are set such that the inlet wind-speed is uniform, and the incident waves are simulated from the JONSWAP wave spectrum. Although the modelling is conducted in the frequency domain, time-series responses are also analysed by emulating them via the superposition of the bodies' responses at individual frequencies. Results are analysed in terms of the maximum power that can be produced given a BA size, as well as how this power generation and BA size changes the motion of the floating wind platform.

This work is presented as follows: Section 2 outlines the materials and methods, which contains a description of the problem, the mathematical model, the tests analysed, and the assumptions of the model. Section 3 outlines the results under a range of wave conditions, which are presented with respect to the wave power that is extracted by the hybrid system, the optimal BA size, the optimal PTO configuration for wave power generation, and the influence the BA has on the spar's motion. Section 4 contains further discussion of the results and model, as well as the main conclusions of the study.

\section{Materials and Methods}

\subsection{Problem Description}

A schematic of the model is shown in Figure 1. The model consists of the NREL OC3 spar type floating wind turbine and a cylindrical floating BA. Locations are defined using a Cartesian co-ordinate system centred at the spar's undisturbed centre of mass but elevated to the still water line (SWL). The co-ordinate system is such that the $z$-direction points in the direction opposite gravity and the $x$-direction points in the direction of wave propagation. For simplicity, it is assumed that the wind propagates in the same direction of the waves, the waves are long crested, and the BA's centre of mass (CoM) is located a distance $\Delta x$ from the spar's CoM, such that the problem is two-dimensional with respect to body motion. The key parameters for the spar are outlined in [9] and the parameters that pertain to this model are summarised in Table 1. This table also gives a definition of the water depth, $\psi=320 \mathrm{~m}$, which is the operational depth of the OC3 spar as defined in [9].

Table 2 gives a summary of the key BA parameters (where $\rho_{w}=1025 \mathrm{~kg} \mathrm{~m}^{-3}$ is the density of water and $g=9.81 \mathrm{~m} \mathrm{~s}^{-2}$ is the acceleration due to gravity). In this table, the BA moment of inertia and centre of mass are approximated from the equivalent mass/volume of water displaced and, in reality, the CoM should be expected to be slightly farther below the SWL and the moment of inertia slightly larger because of the the body's outer structure. Furthermore, note that in this table and this work, the freeboard of the BA is left undefined. This is because the freeboard itself has no influence on the hydrodynamics used in this model and, because of this, it is also assumed that the wind swept area is designed to be small (relative to the water plane area), such that the wind forces on the BA is negligible. 
Table 1. Spar design parameters.

\begin{tabular}{ccc}
\hline Parameter & Symbol & Value \\
\hline Spar draft & $D_{\text {spar }}$ & $120 \mathrm{~m}$ \\
Spar radius below taper & $R_{\text {spar }}$ & $4.7 \mathrm{~m}$ \\
Spar radius above taper & $(-)$ & $3.25 \mathrm{~m}$ \\
Location of taper & $(-)$ & between 4 and $12 \mathrm{~m} \mathrm{depth}$ \\
Spar centre of mass location & $z_{\text {spar }}$ & $78 \mathrm{~m} \mathrm{below} \mathrm{the} \mathrm{SWL}$ \\
Spar mass & $m_{\text {spar }}$ & $8.07 \times 10^{6} \mathrm{~kg}$ \\
Spar moment of inertia & $I_{\text {spar,y }}$ & $6.80 \times 10^{10} \mathrm{~kg} \mathrm{~m}^{2}$ \\
Water depth below SWL & $\psi$ & $320 \mathrm{~m}$ \\
\hline
\end{tabular}

Table 2. BA design parameters.

\begin{tabular}{ccc}
\hline Parameter & Symbol & Value \\
\hline BA draft & $D_{B A}$ & Independent variable \\
BA radius & $R_{B A}$ & Independent variable \\
BA mass & $m_{B A}$ & $\pi R_{B A}^{2} D_{B A} \rho_{w}$ \\
BA moment of inertia & $I_{B A, y}$ & $m_{B A} R_{B A}^{2} / 4+m_{B A} D_{B A}^{2} / 12$ \\
BA centre of mass location & $z_{B A}$ & $D_{B A} / 2$ below the SWL \\
\hline
\end{tabular}

To enable a generic model for the wave energy conversion, it is assumed that the mechanical coupling/PTO system of the WEC system can be modelled using the standard simplified convention of a linear spring and damper system [22], as shown in Figure 1. As the spar is long and narrow, we only consider spring and damper connections about its centreline. These connection points down the centreline of the spar are defined as the distance $L_{k}$ and $L_{b}$ below the SWL for the spring and damper, respectively. In principle, the spring and damper could be attached to any location on the BA's body. However, in order to remove the complexities that are created by coupling the power take-off to the BA's pitch, only the spring and damper connections through the BA's CoM are considered in this study.

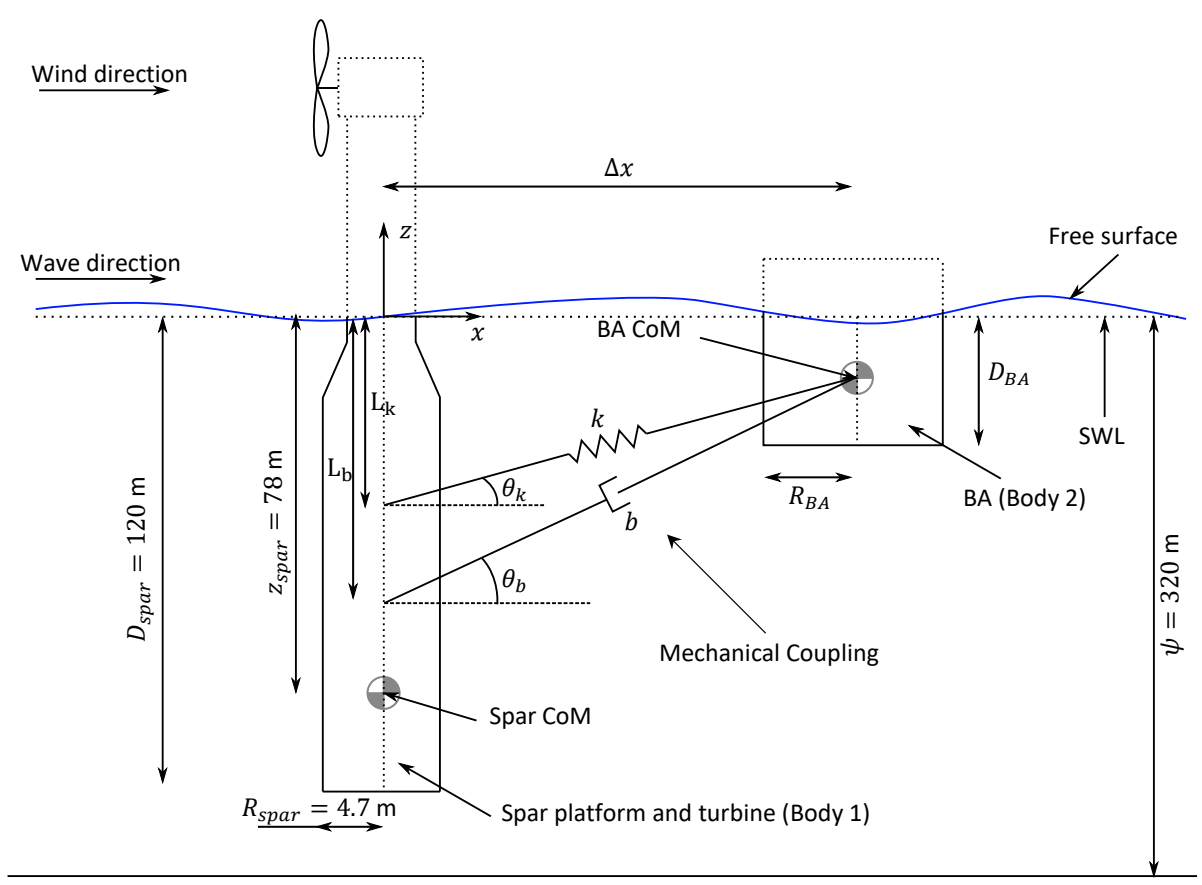

Figure 1. Representative schematic of the problem (not to scale). 


\subsection{Mathematical Model}

This kind of wind and wave energy system can be modelled to various levels of fidelity using either time or frequency domain models [22]. Time domain models (e.g., the Cummins' equation models or computational fluid dynamics models) are higher fidelity because of their ability to model nonlinear forces, but are more computationally demanding. Frequency domain models are significantly faster computationally, but are of lower fidelity because they require the linearisation of forces about the equilibrium, which is valid under the assumption of small wave and body motions [22,23]. Considering that the focus of this work is to investigate the feasibility of the hybrid systems' capabilities, and that this requires consideration of a wide range of parameters (i.e., BA size, wave conditions, associated PTO parameters, etc.), this work uses the standard frequency domain modelling approach.

As the motion of each body is effectively two dimensional (although the model is not entirely two-dimensional due to three-dimensional wave scattering), each body's dynamics are defined in term of their surge, heave, and pitch about their centre of mass. Hence, let the (complex) displacement of the spar and BA at frequency $\omega_{i}$ be defined by the vector

$$
\mathbf{x}\left(\omega_{i}\right)=\left(x_{s 1}\left(\omega_{i}\right), x_{s 3}\left(\omega_{i}\right), x_{s 5}\left(\omega_{i}\right), x_{b 1}\left(\omega_{i}\right), x_{b 3}\left(\omega_{i}\right), x_{b 5}\left(\omega_{i}\right)\right)^{T},
$$

where subscripts $s 1, s 3$, and $s 5$ refer to the spar's surge, heave, and pitch, respectively, and subscripts $b 1, b 3$, and $b 5$ refer to the BA's surge, heave, and pitch, respectively. The motion of these bodies at the frequency $\omega_{i}$ can be described in the standard frequency domain form as $[22,23]$

$$
-\omega_{i}^{2}(M+A) \mathbf{x}\left(\omega_{i}\right)+\mathrm{i} \omega_{i}\left(B_{R}+B_{W}+B_{C}+B_{M}\right) \mathbf{x}\left(\omega_{i}\right)+\left(K_{M}+K_{C}+K_{H}\right) \mathbf{x}\left(\omega_{i}\right)=\mathbf{f}_{e}
$$

where the matrices/vector in this equation, which account for wind forcing, wave forcing, inertia, PTO forcing, and mooring, are outlined in Table 3. The calculation of each of these terms is given in the proceeding subsections.

Note that, in this stage of the modelling process, it is assumed that viscous drag forces on the bodies are negligible under the assumption that body motions are small relative to the motion of the surrounding waves. The usefulness of this assumption is that (i) it ensures that body motions are linear with respect to wave amplitude, (ii) it ensures that wave power generation is linear with respect to wave amplitude squared, (iii) this therefore allows the results to be run and analysed without adding an additional independent variable of wave height, (iv) including viscous drag forces into a frequency domain model is a computationally demanding iterative process which significantly reduces the performance of the algorithm $[22,24,25]$, and (v) this therefore creates significant issues in calculating the optimal (with respect to power generation) BA size and PTO configuration as the problem has a large number of independent variables to process. Nonetheless, viscous drag forces will be added to this model and presented at the end of the results section to validate this assumption that viscous drag can be neglected for this analysis.

Table 3. Frequency domain variables.

\begin{tabular}{cl}
\hline Variable & Description \\
\hline$M$ & Mass matrix \\
$A$ & Added mass matrix \\
$B_{R}$ & Radiation damping matrix \\
$B_{W}$ & Wind damping matrix \\
$B_{C}$ & Mechanical coupling damping matrix \\
$B_{M}$ & Mooring added damping matrix \\
$K_{M}$ & Mooring stiffness matrix \\
$K_{C}$ & Mechanical coupling stiffness matrix \\
$K_{H}$ & Hydrostatic stiffness matrix \\
$\mathbf{f}_{e}$ & Excitation force vector \\
\hline
\end{tabular}




\subsubsection{Mass Matrix}

The mass matrix is defined as

$$
M=\operatorname{diag}\left(m_{\text {spar }}, m_{\text {spar }}, I_{\text {spar }, y}, m_{B A}, m_{B A}, I_{B A, y}\right),
$$

where these masses and moments of inertia were defined in the problem description of Tables 1 and 2 in Section 2.1.

\subsubsection{Added Mass, Radiation Damping, and Wave Excitation Force}

The frequency dependent added mass matrix $(A)$, radiation damping matrix $\left(B_{R}\right)$, and excitation force vector $\left(\mathbf{f}_{e}\right)$ are calculated by the boundary element method code $\mathrm{NEMOH}$ [26]. This code is used because it is open-source and has been validated for floating wind turbine and WEC models [27,28]. Its primary inputs are meshes of the spar and BA bodies, which were created using the open-source meshing package Gmsh. The other input for $\mathrm{NEMOH}$ is the separation distance between the bodies $(\Delta x)$ and the water depth, which allows consideration of the body's hydrodynamic coupling via wave phasing and scattering.

The added mass matrix and radiation damping matrix are raw outputs from NEMOH. The excitation force calculated via $\mathrm{NEMOH}, \mathbf{f}_{W}\left(\omega_{i}\right)$, is scaled by the incident wave amplitude at a given frequency. This allows the wave forcing on the body to be calculated as

$$
\mathbf{f}_{e}\left(\omega_{i}\right)=\left|a\left(\omega_{i}\right)\right| \mathrm{e}^{\mathrm{i} \arg \left(a\left(\omega_{i}\right)\right)} \mathbf{f}_{W}\left(\omega_{i}\right),
$$

where $\left|a\left(\omega_{i}\right)\right|$ and $\arg \left(a\left(\omega_{i}\right)\right)$ are the amplitude and phase of the incident wave spectrum at frequency $\omega_{i}$, respectively. For this work, the wave spectrum is taken as the commonly used JONSWAP spectrum with the standard peak enhancement factor of $\gamma=3.3$ [29]. Hence, it is defined in terms of some specified peak period $T_{p}$ and significant wave height $H_{s}$, and the explicit form of $a\left(\omega_{i}\right)$ this JONSWAP spectrum description gives is presented in Appendix A.

A validation of these coefficients was performed (not shown) with respect to the known spar coefficients from [9] and the analytic coefficients of the BA from the solution of [30].

\subsubsection{Hydrostatic Stiffness Matrix}

Each body has a hydrostatic stiffness as they have a non-zero freeboard (i.e., they are surface piercing). For the spar, the hydrostatic stiffness matrix is calculated from $\mathrm{NEMOH}$ (and is consistent with [31]). Its entries are

$$
K_{H, \text { spar }}=\left[\begin{array}{ccc}
0 & 0 & 0 \\
0 & 3.33 \times 10^{5} \mathrm{~N} \mathrm{~m}^{-1} & 0 \\
0 & 0 & 1.33 \times 10^{9} \mathrm{~N} \mathrm{~m} \mathrm{rad}^{-1}
\end{array}\right] .
$$

For the cylinder, the hydrostatic stiffness is calculated analytically as [22]

$$
K_{H, B A}=\left[\begin{array}{ccc}
0 & 0 & 0 \\
0 & \rho g \pi R_{B A}^{2} & 0 \\
0 & 0 & \rho g \pi R_{B A}^{3} / 3-\rho g \pi R_{B A}^{2} D_{B A} / 2-g m_{2} z_{B A, b}
\end{array}\right],
$$

where $z_{B A, b}=-D_{B A} / 2$ is the centre of mass of the BA. The overall hydrostatic stiffness matrix is given by

$$
K_{H}(\omega)=\left[\begin{array}{cc}
K_{H, s p a r} & \mathbf{0}_{3 \times 3} \\
\mathbf{0}_{3 \times 3} & K_{H, B A}
\end{array}\right]
$$




\subsubsection{Mooring Matrix}

The mooring system connects the spar to the seabed. Without the presence of a BA, this mooring system has been defined in [31], and it is assumed that this design is also appropriate for the hybrid spar-BA system. This mooring system is a three tethered gravity anchored catenary configuration. The cables in this system have a weight in water of $698 \mathrm{~N} \mathrm{~m}^{-1}$, diameter of $0.09 \mathrm{~m}$, and an equivalent extensional stiffness of $3.84 \times 10^{8} \mathrm{~N}$. They are attached to the spar at a depth of $70 \mathrm{~m}$ below the SWL, to the seabed along a radius of $853 \mathrm{~m}$ from the spar's centreline, and are spaced $120 \mathrm{deg}$ from each other.

Its stiffness matrix is adapted from [31], which uses the linearisation calculation method of [32]. It is adapted (rather than directly taken) from [31] because that report used pitching force calculations about the spar's centre of mass ( $90 \mathrm{~m}$ below the SWL) instead of the combined centre of mass of the spar plus turbine (78 m below the SWL). Accordingly, this work uses the results from [31], but with the centre of mass adjusted to $78 \mathrm{~m}$ below the SWL. With this correction, the $6 \times 6$ mooring stiffness matrix is given as

$$
\begin{array}{ll}
K_{M,(1,1)}=4.12 \times 10^{4} \mathrm{~N} \mathrm{~m}^{-1}, & K_{M,(1,3)}=3.96 \times 10^{5} \mathrm{~N} \mathrm{rad}^{-1}, \\
K_{M,(2,2)}=1.19 \times 10^{4} \mathrm{~N} \mathrm{~m}^{-1}, & K_{M,(3,1)}=3.96 \times 10^{5} \mathrm{~N} \mathrm{~m} \mathrm{~m}^{-1}, \\
K_{M,(3,3)}=1.22 \times 10^{8} \mathrm{~N} \mathrm{~m} \mathrm{rad}^{-1} &
\end{array}
$$

and is zero for all other entries (note that it is zero for entries related to 4-6 because, in this model, the BA is connected to the spar and not moored to the seabed).

In addition, it is known from [31] that the mooring also produces some additional damping effects. These are prescribed through the $6 \times 6$ mooring stiffness matrix, which is given as

$$
B_{M,(1,1)}=1.0 \times 10^{5} \mathrm{Ns} \mathrm{m}^{-1}, \quad B_{M,(2,2)}=1.3 \times 10^{5} \mathrm{~N} \mathrm{~s} \mathrm{~m}^{-1},
$$

and zero for all other matrix entries.

\subsubsection{Wind Force Damping Matrix}

Consistent with prior floating wind turbine studies (e.g., [33]), it is assumed that the turbulent drag around the tower is negligible, that the inlet wind speed is uniform, that it's direction is parallel to the $x$-direction, that wind forces do not produce non-negligible sway or yaw forces, and that the tower is pre-weighted such that it is upright under rated wind conditions. Accordingly, the wind forcing can be modelled using the standard blade element momentum (BEM) method [23], with the blade profiles given from the NREL 5MW rotors that are given in [9]. Therefore, the thrust force has the form

$$
F_{T}\left(V_{e}(t)\right)=\frac{\rho_{a} \pi R_{r}^{2}}{2} C_{T}\left(\frac{\Omega_{r} R_{r}}{V_{e}(t)}, \beta\right) V_{e}(t)^{2},
$$

where $\rho_{a}=1.225 \mathrm{~kg} \mathrm{~m}^{-3}$ is the density of air, $R_{r}=63 \mathrm{~m}$ is the radius of the rotor, $\Omega_{r}$ is the angular velocity of the rotor, $\beta$ is the pitch angle of the rotor, $V_{e}=v_{w}-v_{n}$ is the speed of the nacelle relative to the inlet wind speed, and $C_{T}$ is the non-dimensional thrust coefficient that is calculated through the BEM method.

This thrust forcing is nonlinear with respect to the motion of the spar. Thus, Equation (10) is linearised for use in the frequency domain model. This is performed by taking a Taylor expansion with respect to the $V_{e}$ term about some $V_{e}=v_{w}$ point, which gives

$$
F_{T}\left(V_{e}\right)=F_{T}\left(v_{w}\right)+\frac{\mathrm{d} F_{T}\left(v_{w}\right)}{\mathrm{d} V_{e}}\left(-v_{n}\right)+O\left(v_{n}^{2}\right) .
$$

Under the assumption that tower motions are small the $O\left(v_{n}^{2}\right)$ term is negligible, and, under the assumption that the tower is pre-weighted such that the mean wind force does not perturb it from the upright position, the $F_{T}\left(v_{w}\right)$ term is not required in this model as it 
is a constant mean force. Therefore, the thrust force of the wind in the frequency domain is given as

$$
F_{T}=\frac{\mathrm{d} F_{T}\left(v_{w}\right)}{\mathrm{d} V_{e}}\left(-\mathrm{i} \omega x_{s 1}+\mathrm{i} \omega L_{n} x_{s 5}\right),
$$

where $L_{n}=168 \mathrm{~m}$ is the distance from the spar's centre of mass to nacelle. This thrust force also generates a corresponding moment about the spar's centre of mass. Assuming small motions, this is given as

$$
M_{T}=L_{n} F_{T}=L_{n} \frac{\mathrm{d} F_{T}\left(v_{w}\right)}{\mathrm{d} V_{e}}\left(-\mathrm{i} \omega_{i} x_{s 1}+\mathrm{i} \omega_{i} L_{n} x_{s 5}\right) .
$$

These descriptions therefore allow the wind's thrust and torque to be calculated with respect to the variables $x_{s 1}$ and $x_{s 5}$ via numerical differentiation of Equation (10) about the point $V_{e}=v_{w}$. For simplicity, this work only uses the rated wind conditions of the NREL OC3 design. These are $v_{w}=11.4 \mathrm{~m} \mathrm{~s}^{-1}$, for which the turbine rotates with $\Omega_{r}=12.1 \mathrm{rpm}$ and $\beta=0$. Such conditions give

$$
\frac{\mathrm{d} F_{T}\left(v_{w}\right)}{\mathrm{d} V_{e}}=81,920 \mathrm{~N} \mathrm{~s} \mathrm{~m}^{-1},
$$

and, therefore, Equations (12) and (13) give the linearised wind damping force in the frequency domain as

$$
\begin{array}{ll}
B_{W,(1,1)}=8.19 \times 10^{4} \mathrm{Ns} \mathrm{m}^{-1}, & B_{W,(3,1)}=-1.37 \times 10^{7} \mathrm{~N} \mathrm{~s} \mathrm{rad}^{-1}, \\
B_{W,(1,3)}=-1.37 \times 10^{7} \mathrm{Ns}, & B_{W,(3,3)}=2.31 \times 10^{9} \mathrm{~N} \mathrm{~m} \mathrm{~s} \mathrm{rad}^{-1},
\end{array}
$$

and zero for all other entries.

Note that, although this work only uses the rated wind speed of $11.4 \mathrm{~m} \mathrm{~s}^{-1}$, a sensitivity study was performed for other wind speeds, blade angles, and rotor speeds. It was found that for wind speeds between 3 and $25 \mathrm{~m} \mathrm{~s}^{-1}$, the entries in $B_{W}$ would vary by less than $15 \%$. It was also found that this variance would affect the WEC power generation by less than $5 \%$, and would have minimal impact on the spar and WEC's motion. This is why this work only uses the aforementioned values of $B_{W}$ for $v_{w}=11.4 \mathrm{~m} \mathrm{~s}^{-1}, \beta=0$, and $\Omega_{r}=12.1 \mathrm{rpm}$.

\subsubsection{Mechanical Coupling Matrices}

The mechanical coupling system, which models the PTO system, is approximated by a generic spring and damper system, with the geometry outlined in Section 2.1 and shown in Figure 1. Accordingly, when these forces are linearised they result in the coupling matricies

$$
\frac{K_{C}}{k}=\left[\begin{array}{cccccc}
\cos \theta_{k} & 0 & -\left(z_{\text {spar }}-L_{k}\right) \cos \theta_{k} & -\cos \theta_{k} & 0 & 0 \\
0 & \sin \theta_{k} & 0 & 0 & -\sin \theta_{k} & 0 \\
-\left(z_{\text {spar }}-L_{k}\right) \cos \theta_{k} & 0 & \left(z_{\text {spar }}-L_{k}\right) \cos ^{2} \theta_{k} & \left(z_{\text {spar }}-L_{k}\right) \cos \theta_{b} & 0 & 0 \\
-\cos \theta_{k} & 0 & \left(z_{\text {spar }}-L_{k}\right) \cos \theta_{k} & \cos \theta_{k} & 0 & 0 \\
0 & -\sin \theta_{k} & 0 & 0 & \sin \theta_{k} & 0 \\
0 & 0 & 0 & 0 & 0 & 0
\end{array}\right]
$$




$$
\frac{B_{C}}{b}=\left[\begin{array}{cccccc}
\cos \theta_{b} & 0 & -\left(z_{\text {spar }}-L_{b}\right) \cos \theta_{b} & -\cos \theta_{b} & 0 & 0 \\
0 & \sin \theta_{b} & 0 & 0 & -\sin \theta_{b} & 0 \\
-\left(z_{\text {spar }}-L_{b}\right) \cos \theta_{b} & 0 & \left(z_{\text {spar }}-L_{b}\right) \cos ^{2} \theta_{b} & \left(z_{\text {spar }}-L_{b}\right) \cos \theta_{b} & 0 & 0 \\
-\cos \theta_{b} & 0 & \left(z_{\text {spar }}-L_{b}\right) \cos \theta_{b} & \cos \theta_{b} & 0 & 0 \\
0 & -\sin \theta_{b} & 0 & 0 & \sin \theta_{b} & 0 \\
0 & 0 & 0 & 0 & 0 & 0
\end{array}\right],
$$

where $k$ is the spring stiffness coefficient, $b$ is the damping coefficient, the distances $L_{b}$, $L_{k}$, and $z_{\text {spar }}=78 \mathrm{~m}$ are as described in Section 2.1, and $\theta_{b}$ and $\theta_{k}$ are defined through the geometry such that

$$
\theta_{k}=\tan ^{-1}\left(\frac{\left(L_{k}-z_{B A}\right)}{\Delta x}\right) \text { and } \theta_{b}=\tan ^{-1}\left(\frac{\left(L_{b}-z_{B A}\right)}{\Delta x}\right) .
$$

\subsubsection{Solving for Motion, RAOs, and Power}

The motion of the bodies in the frequency domain is defined via Equation (2). Therefore, the motion at a given frequency $\omega_{i}$ is solved as

$$
\mathbf{x}\left(\omega_{i}\right)=\left[-\omega_{i}^{2}\left(M+A\left(\omega_{i}\right)\right)+\mathrm{i} \omega_{i}\left(B_{R}\left(\omega_{i}\right)+B_{W}+B_{C}+B_{M}\right)+\left(K_{M}+K_{C}+K_{H}\right)\right]^{-1} \mathbf{f}_{e}\left(\omega_{i}\right) .
$$

This allows the response amplitude operator at the frequency $\omega_{i}, \mathbf{R A O}\left(\omega_{i}\right)$, to be calculated as

$$
\mathbf{R A O}\left(\omega_{i}\right)=\mathbf{x}\left(\omega_{i}\right) /\left|a\left(\omega_{i}\right)\right|,
$$

where the first three entries of the $\mathbf{R A O}\left(\omega_{i}\right)$ vector correspond to the surge, heave, and pitch of the spar, and the final three entries correspond to the surge, heave, and pitch of the BA.

By the standard procedure for converting between frequency and time domain [22], the motion in the time domain, $\tilde{\mathbf{x}}(t)$, is emulated numerically through the superposition of each individual frequency (as calculated in Equation (19)) as

$$
\tilde{\mathbf{x}}(t)=\sum_{i=1}^{N}\left(\mathbf{x}\left(\omega_{i}\right) \mathrm{e}^{\mathrm{i} \omega_{i} t}\right)
$$

for some large but finite set of $N \omega_{i}$ 's. Note that this work uses 120 values of $\omega_{i}$ spaced evenly between 0.001 and $2 \mathrm{rad} \mathrm{s}^{-1}$. Such values were used because results converged to within $1 \%$ of the results found using 240 values of $\omega_{i}$ spaced evenly between 0.001 and $2 \mathrm{rad} \mathrm{s}^{-1}$.

With respect to power generation, it is assumed that the power generated through the abstracted PTO system is $100 \%$ efficient and that power is generated through the damper. This implies that the average power generated is given by

$$
P_{W E C}=\frac{1}{T_{\text {end }}} \int_{0}^{T_{\text {end }}} \dot{\tilde{\mathbf{x}}}^{T} B_{C} \dot{\tilde{\mathbf{x}}} \mathrm{d} t
$$

where, formally, $T_{\text {end }} \rightarrow \infty$, but to approximate a large $T_{\text {end }}$, this work uses a value of $T_{\text {end }}$ that is large enough that doubling it does not change $P_{W E C}$ by more than $1 \%$ (found to consistently require approximately 100 wave periods).

\subsection{Tests Considered}

The independent variables of the investigation are $T_{p}, H_{s}, \Delta x, D_{B A}, R_{B A}, L_{k}, L_{b}, k$, and $b$. For the purpose of optimisation and benchmarking, it is impractical to investigate all these variables along a continuous span. Hence, results for some of these variables are considered along a grid of points. 
For the BA's geometry, results are taken for a BA draft to radius ratio of $D_{B A} / R_{B A} \in$ $[0.25,2]$ in increments of 0.25 , and the radius is taken relative to the spar's radius as $R_{B A} / R_{\text {spar }} \in[0.5,5.5]$ in increments of 0.25 . Tests were not conducted beyond these limits because it was found that for values of $D_{B A} / R_{B A}$ outside these bounds, smaller $P_{W E C}$ results would be obtained (i.e., they always generated less power). Similarly, it was found that for $R_{B A} / R_{\text {spar }}<0.5, P_{W E C}$ would be much lower than the larger radius counterparts, and for $R_{B A} / R_{\text {spar }}>6$ the BA would become impractically large and not necessarily generate any more power than the lower radius counterparts. Noting that the values of $R_{B A}$ and $D_{B A}$ have the potential to give $m_{B A} \gg m_{\text {spar }}$ (such large mass BA results are included as a theoretical exercise), additional radii are also added to satisfy the condition $m_{B A}=m_{\text {spar }}$, which is prescribed as a kind of reasonable upper bound of how heavy the BA can be.

With respect to the mechanical coupling geometry, the linkage distances along the draft of the spar $\left(L_{k}\right.$ and $\left.L_{b}\right)$ are tested in the interval $[0,78] \mathrm{m}$ in $7.8 \mathrm{~m}$ increments, which spans the length between the SWL and the spar's centre of mass. Depths larger than $78 \mathrm{~m}$ are not considered as these are well below the SWL, are below the body's centre of mass, and could add complications when considering the mooring lines. The separation distance is set such that $\Delta x \in[50,150] \mathrm{m}$ with $12.5 \mathrm{~m}$ increments. The closer spacing are prescribed as distances that might be practically achievable (simulations with a separation distance $\leq 37.5 \mathrm{~m}$ between the centres of mass could result in body collisions), and the larger distances are to investigate the effect of wave phasing.

The waves (which, as previously mentioned, are modelled using the JONSWAP spectrum), are tested for $T_{p} \in[8,14] \mathrm{s}$ in $1 \mathrm{~s}$ increments. Such periods are chosen to investigate short to long length waves. For the wave height, this study gathers results from the single value of $H_{s}=2 \mathrm{~m}$; however, as the hydrodynamic modelling is entirely linear, it should be noted that all motion is directly proportional to $H_{s}$ and power generation directly proportional to $H_{S}^{2}$.

The remaining independent variables are $k$ and $b$. The purpose of these variables is to model the PTO and, therefore, be tuned such that $P_{W E C}$ is maximised given the environmental conditions and spar/BA parameters. Therefore, rather than testing these variables on a grid as is conducted for the other independent parameters $R_{B A}, T_{p}$, etc., this work only considers the $k$ and $b$ that maximises $P_{W E C}$ given a selection of the other independent variables. To do this, an optimisation routine is implemented. This routine is non-trivial because testing found $P_{W E C}(k, b)$ to be multimodal (i.e., contain multiple local maxima).

Therefore, a bespoke optimisation routine was implemented to complete the simulation procedure. Such a procedure is outlined in the flowchart shown in Figure 2. In this routine, the simulation is first initialised with a choice of $R_{B A}, D_{B A}, \Delta x, L_{k}, L_{b}, T_{p}$, and $H_{s}$. NEMOH is then run in order to generate $A, B_{R}$, and $\mathbf{f}_{e}$ and, alongside this, $B_{W}$, $B_{M}, K_{M}, K_{H}, K_{C} / k$, and $B_{C} / b$ are calculated using the methodology described earlier. The power generation problem is then formulated in terms of a function of the form $P_{W E C}(b, k)$, as governed by Equations (19), (21) and (22). A grid of $k=\left[10^{1}, 10^{2}, \ldots, 10^{10}\right] \mathrm{Nm}^{-1}$ and $b=\left[10^{1}, 10^{2}, \ldots, 10^{10}\right] \mathrm{N} \mathrm{s} \mathrm{m}^{-1}$ values (i.e., an 'order of magnitude' grid) are then generated. The $P_{W E C}(b, k)$ function and a choice of an 'initial' $k$ and $b$ from this grid is then input into MATLAB's fmincon algorithm in order to find the local maximum correlated to this 'initial' $k$ and $b$ point. The fmincon function is run for each point on the grid and the largest local maximum and its corresponding $k$ and $b$ values are stored. Manual testing (via plotting the $P_{W E C}(k, b)$ surface) consistently found that this local maximum would be near to, but not exactly at, the global maximum of $P_{W E C}(b, k)$. Therefore, after this search for the maximum on the 'order of magnitude grid' is conducted, another search on a more refined grid is conducted. This search is performed as with the prior search, but for 20 evenly spaced values of both $k$ and $b$ ranging from 0.7 to 1.4 , the $k$ and $b$ values found from the prior largest local maximum. Once completed it was found that this would always result 
in the maximum possible value $( \pm<1 \%)$ of $P_{W E C}(k, b)$, and these corresponding $k$ and $b$ values are therefore used in the simulations and analysis of results.

Select $R_{B A}, D_{B A}, \Delta x, L_{k}, L_{b}, T_{p}$, and $H_{s}$.

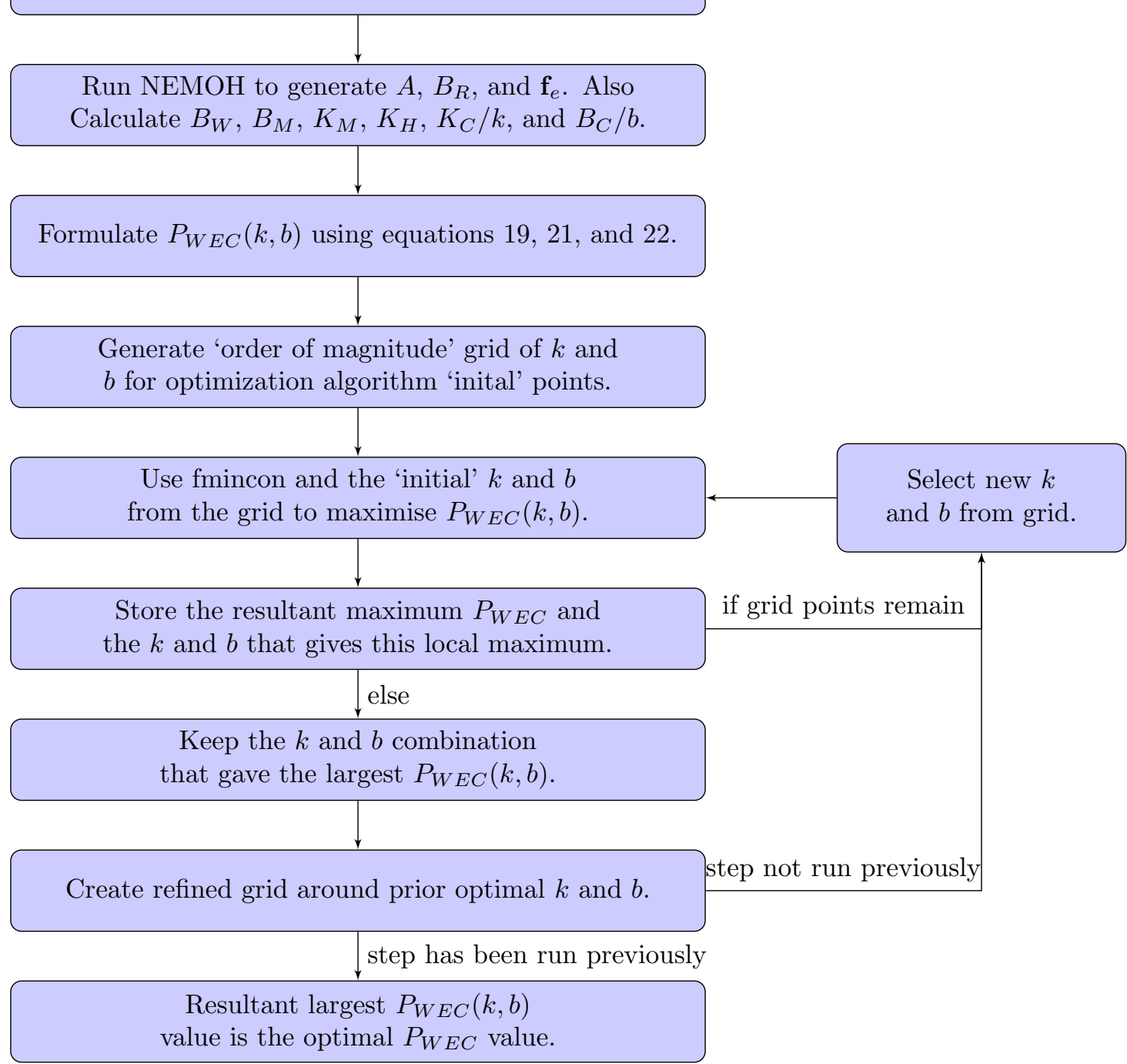

Figure 2. Flowchart of simulation procedure.

\section{Results}

\subsection{Power}

Figure 3 shows heat maps of the maximum power scaled to wave height, $P_{W E C} / H_{s}^{2}$, that can be achieved for over a range of peak wave period and separation distances (note that this $P_{W E C} / H_{S}^{2}$ parameter is used to present these power results because power generation is directly proportional to $H_{S}^{2}$ ). In this figure, individual panels show the power as a function of $R_{B A}$ and $D_{B A} / R_{B A}$, and the panels themselves vary in terms of $\Delta x$ (left to right) as well as $T_{p}$ (top to bottom). Note that in these and future plots, the blue dots indicate the points where the solution was calculated, the heat map/contours are the interpolation between these points, and the red curve is the locus of $m_{\text {spar }}=m_{B A}$.

The plots show that the maximum power that can be achieved across wave period and separation distance varies from approximately $0.09 \mathrm{MW} \mathrm{m}^{-2}$ for $T_{p}=8 \mathrm{~s}$ to $0.16 \mathrm{MW} \mathrm{m}^{-2}$ for $T_{p}=12 \mathrm{~s}$, (which is expected as the longer waves have greater energy [34]). With respect to the separation distance, the plots do not demonstrate any clear conclusions on whether larger or smaller separation distances are more favourable across the range of 
wave periods in general. However, the plots do indicate that, for all waves, the optimal BA sizes are ones with $m_{B A}>m_{\text {spar, }}$, where, for instance, the optimal power generation for $T_{p}=12 \mathrm{~s}$ and $\Delta x=75 \mathrm{~m}$ requires the mass of the BA to be approximately 5.8 times heavier than the spar. With respect to the more physically realistic bound on BA sizes of $m_{B A} \leq m_{\text {spar }}$, the plots show that the power that can be generated is not very sensitive to the BA draft, is maximised at the upper limit of $m_{B A}=m_{s p a r}$, and this power ranges from approximately $0.085 \mathrm{MW} \mathrm{m}^{-2}$ for $T_{p}=8 \mathrm{~s}$ to $0.13 \mathrm{MW} \mathrm{m}^{-2}$ for $T_{p}=12 \mathrm{~s}$. This also means that under the constraint that $m_{B A} \leq m_{\text {spar }}$, the maximum power that can be achieved is approximately 10 to $25 \%$ the amount that could be achieved without this constraint.
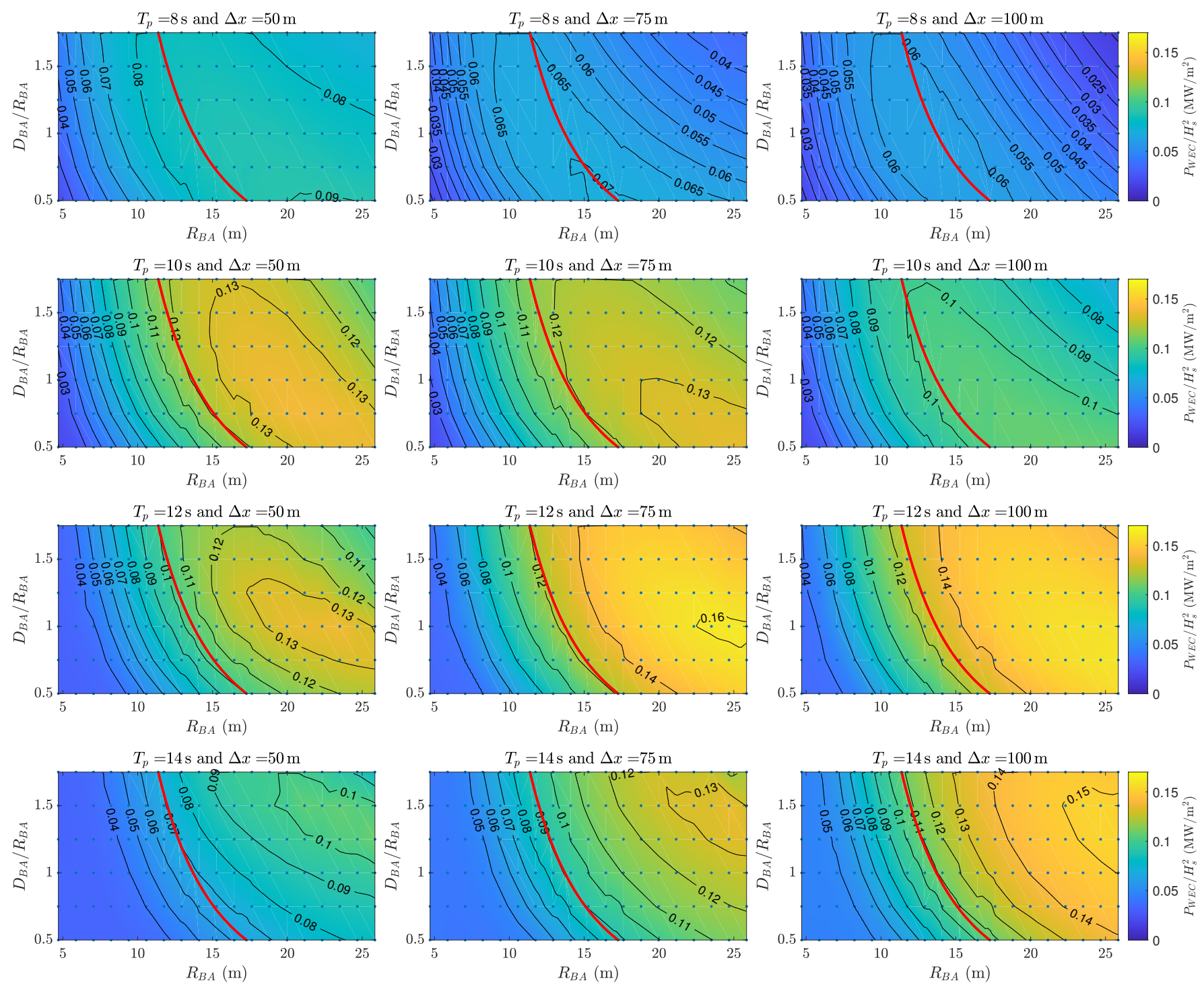

Figure 3. Power (scaled to wave height) generation as a function $R_{B A}$ and $D_{B A}$. Left to right: varied separation distances. Top to bottom: varied peak wave period. Red curve is the locus of $m_{s p a r}=m_{B A}$.

Figure 4 provides a more focused look at the power production for this bound of $m_{B A}=m_{\text {spar }}$ (the BA size that produces the most power under the equal or less than mass constraint). Its individual plots shows the power that can be produced for all these BA cases as a function of $T_{p}$, and the panels vary in terms of the separation distance. These plots again demonstrate that there is only a small difference in power generation for all the $m_{B A}=m_{\text {spar }}$ sizes; however, it does show that, across almost all cases, the optimal BA size is that which has $D_{B A} / R_{B A}=1$ and corresponding $R_{B A}=13.7 \mathrm{~m}$. For this BA size, it shows that the optimal power production favours a nearer separation distance for shorter 
period waves and a farther separation distance for longer period waves. However, the separation distance only accounts for a power generation variation of approximately $10 \%$ when averaged across all cases. The panels also show that across the range of waves tested, the most power that can be generated is $0.13 \mathrm{MW} \mathrm{m}^{-2}$, which is for the $T=12 \mathrm{~s}$ waves and $\Delta x=75 \mathrm{~m}$. When the wave height scaling is removed, this gives power generation of $P_{W E C}=0.13,0.52$, and $1.17 \mathrm{MW}$ for $H_{s}=1,2$, and $3 \mathrm{~m}$, respectively. It therefore indicates that it is theoretically possible for the wave energy system to produce power in the same order of magnitude of the wind energy system (which is rated at $5 \mathrm{MW}$ ) for more high amplitude waves with $H_{s}$ nearing or exceeding $3 \mathrm{~m}$. However, this is for the wave period that generates the most power. In contrast, when averaging across all wave periods, the generation of the $D_{B A} / R_{B A}=1$ sized BAs gives $P_{W E C} / H_{s}^{2} \approx 0.1 \mathrm{MW} \mathrm{m}^{-2}$. This indicates that the power that might be expected from the BA ranges from 0.1 to $0.9 \mathrm{MW}$ for a significant wave height that varies from 1 to $3 \mathrm{~m}$, which is approximately an order of magnitude less than the $5 \mathrm{MW}$ rating of the wind energy system. Therefore, while it can be seen that the wave energy system can potentially generate power in the same order of magnitude as the wind energy system, it is more likely to generate around $10 \%$ of what the wind energy system can achieve.
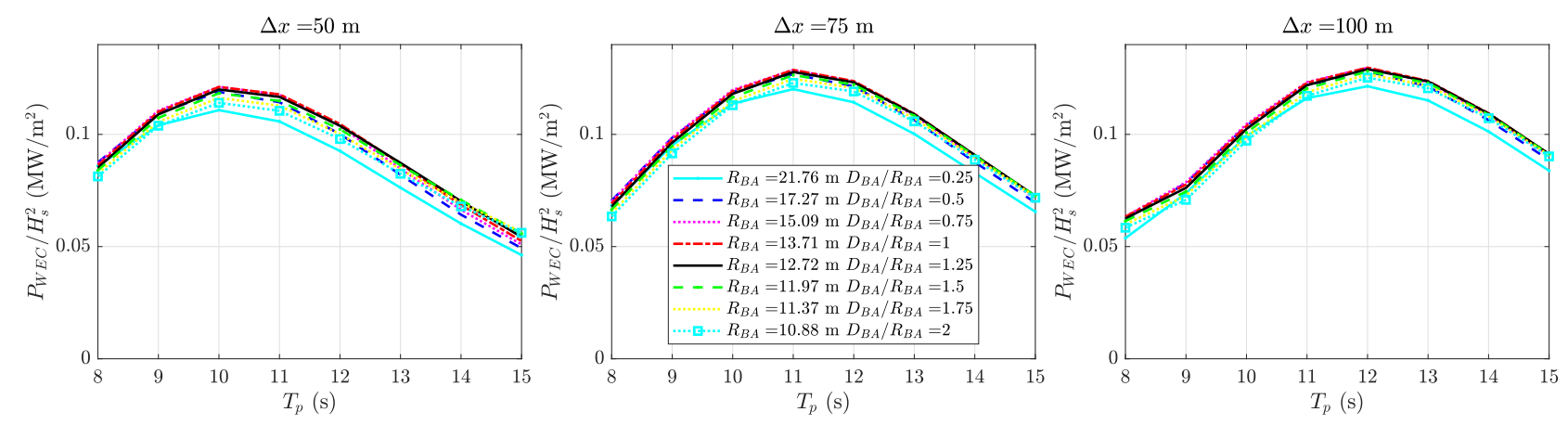

Figure 4. Power (scaled to wave height) generation as a function of peak period for varied $R_{B A}$ and $D_{B A}$ values (as per legend). Left to right: varied separation distances.

Figure 5 is as in Figure 3 but for the relative capture width, $R C W$, rather than the power generated. The $R C W$ is defined as [22]

$$
R C W=P_{W E C} / P_{\text {in }}
$$

where $P_{\text {in }}$ is the power incident upon the width of the BA, which is defined as

$$
P_{\text {in }}=\sum_{i=1}^{N} R_{B A} \rho_{w} g\left|a\left(\omega_{i}\right)\right|^{2}\left[\frac{\omega_{i}}{2 k_{i}}\left(1+\frac{2 k_{i} \psi}{\sinh \left(2 k_{i} \psi\right)}\right)\right],
$$

where $k_{i}$ satisfies the dispersion relationship $k_{i} \tanh \left(k_{i} \psi\right)=w_{i}^{2} / g$ [34]. This $R C W$ is the conventionally used metric for the efficiency of the WEC with respect to its size.

The results displayed in Figure 5 show that the $R C W$ peaks for $m_{B A}<m_{\text {spar }}$ for $T_{p}<12 \mathrm{~s}$ and peaks at about $m_{B A}=m_{s p a r}$ for $T_{p}=14 \mathrm{~s}$. They also show that the $R C W$ peaks for $D_{B A} / R_{B A} \geq 2.00$. Note that, in some regions, the $R C W$ is greater than 1 . This occurs because, even though the model is mostly two-dimensional, it does incorporate three-dimensional wave scattering effects about the BA, which allows energy capture larger than the energy incident upon the cross section of the BA (this has been observed in other studies, e.g., [35]). In contrast with the results displayed in Figure 3, this indicates that while larger powers can be obtained from heavier and relatively squat BAs, the most efficient $\mathrm{BA}$ size, as governed by the $R C W$, is a more elongated and narrow cylinder (similar results have been observed for BAs acting in isolation in, e.g., [35]). A potential consequence of this is that attaching the spar to multiple smaller BAs (rather than a single larger one) might be a more effective strategy for power generation with respect to efficiency. 

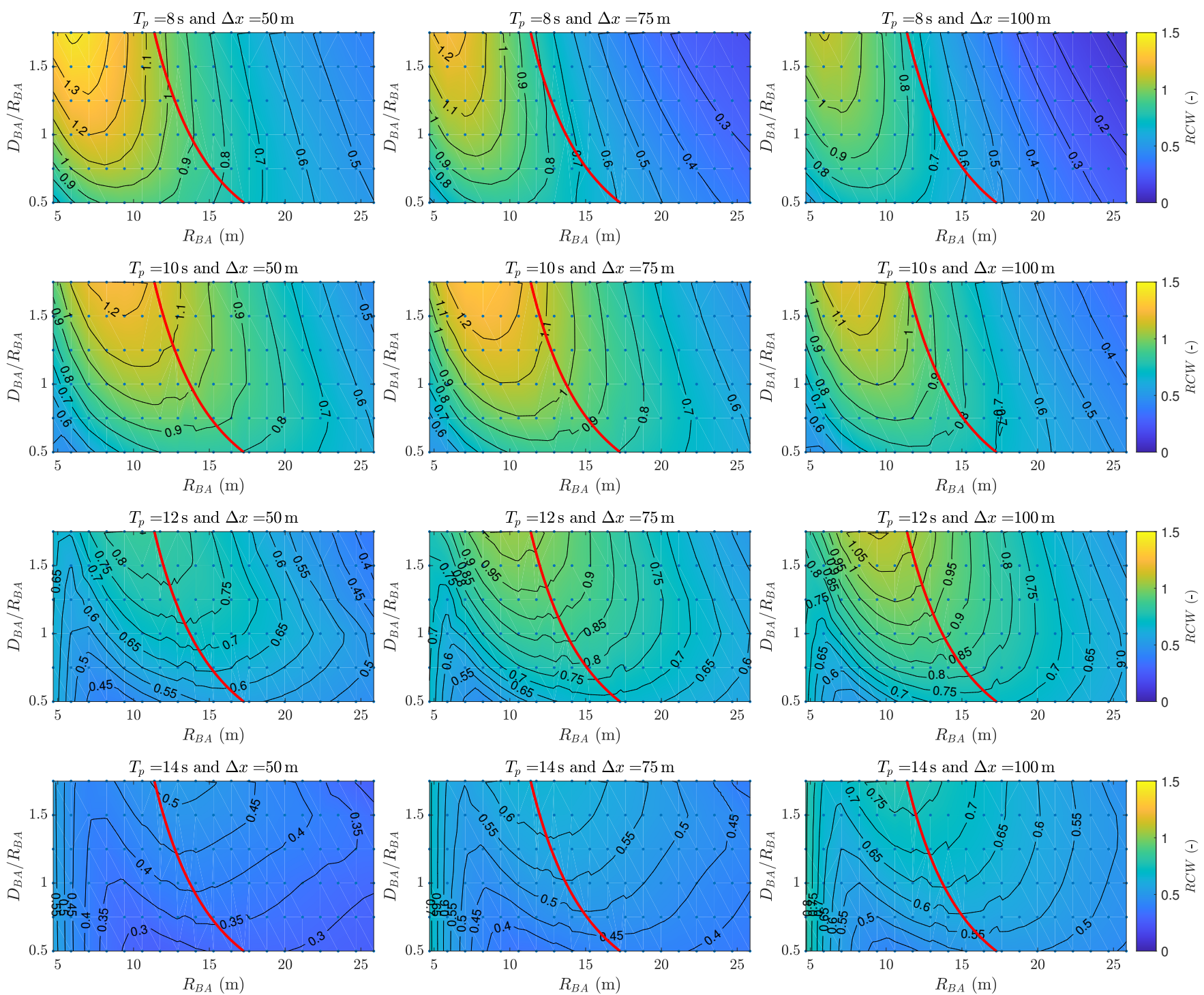

Figure 5. As in Figure 3 but for the relative capture width instead of the power generated.

\subsection{Mechanical Coupling}

Figure 6 shows the maximum power production as a function of $L_{k}$ and $L_{b}$ for varied $R_{B A}$ (left to right panels) for the cases where $D_{B A} / R_{B A}=1.00, T_{p}=12 \mathrm{~s}$, and $\Delta x=50 \mathrm{~m}$. For all cases, the plots show that the optimal power generation occurs for $L_{k}=L_{b}=78 \mathrm{~m}$. This was found to be true of all BA sizes and waves tested. This, therefore, implies that the optimal connection with respect to power production is that between the BA CoM and the spar's CoM, which also tends to indicate that power is being generated through both the relative surge and heave motions of the BA and spar. From a design perspective, this is unfortunate as the plots also show that the connection point from the SWL $\left(L_{k}=L_{b}=0\right.$, which might be more easily engineered) to the BA produces only $40 \%$ of the power that can be produced from the $L_{k}=L_{b}=78 \mathrm{~m}$ connection point. 

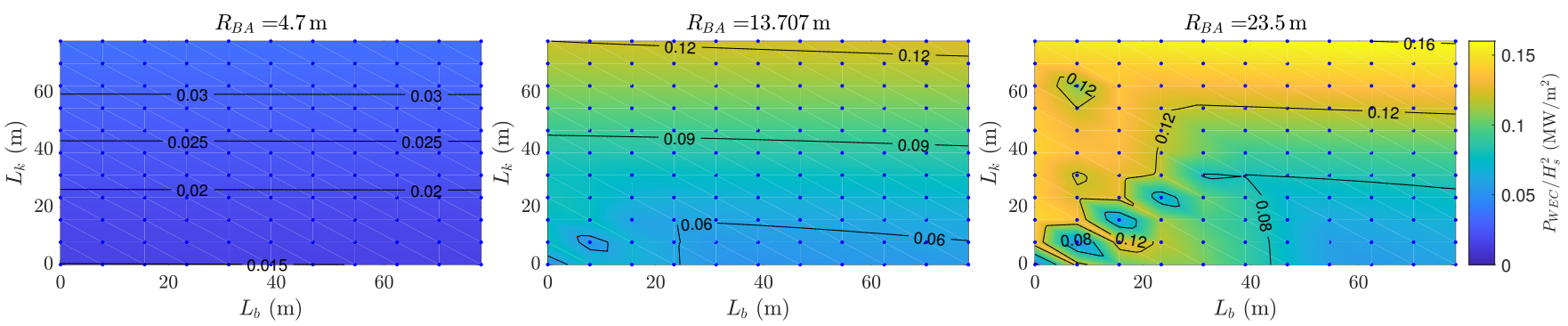

Figure 6. Power generated as a function of $L_{k}$ and $L_{b}$ for tests with, $D_{B A} / R_{B A}=1.00, T_{p}=12 \mathrm{~s}$, and $\Delta x=50 \mathrm{~m}$. Left to right: varied values of BA radius.

Figure 7 shows the maximum power that can be generated for various BA sizes (left to right) as a function of $T_{p}$ (note that because these are the cases for maximum power, they are for $L_{k}=L_{b}=78 \mathrm{~m}$ ). These plots have curves that show the comparison of connection distances $(\Delta x)$, but also have curves that show the maximum power that could be generated if the BA was connected to a fixed structure and power was taken from purely surge or heave motion. These were calculated by using the same model discussed earlier, but without the degrees of freedom for the spar body and setting $\theta_{k}=\theta_{b}=0^{\circ}$ for surge and $\theta_{k}=\theta_{b}=90^{\circ}$ for heave. It is presented to give a comparison as to whether the moving spar body enhances or reduces potential wave power generation. It shows that, except for the cases when $T_{p}<11$ and $R_{B A}=4.7 \mathrm{~m}$, the BA motion produces less power when connected to the spar than it can from a surge coupling to a fixed body. However, it also shows that the BA produces more power than it would if operating with heave connection to the seabed. Therefore, overall, it demonstrates that the spar motion is not necessarily amplifying power production when compared to that which might be generated from a connection to a fixed body.
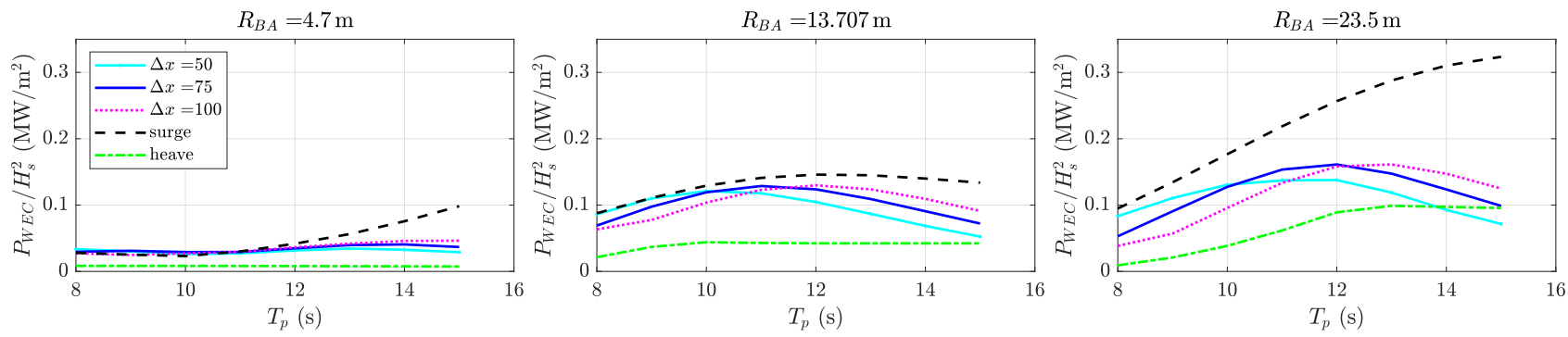

Figure 7. Power as a function of peak period for $D_{B A} / R_{B A}=1.00$ and varied separation distance or pure surge/heave coupling. Left to right: varied BA radius.

\subsection{Motion}

Figures 8-10 show the RAOs (left) and sample time series of the motion (right) of the spar and BA, before and after the coupling is introduced for cases where $\Delta x=50 \mathrm{~m}$, $L_{k}=L_{b}=78 \mathrm{~m}, T_{p}=12 \mathrm{~s}$, and $k$ and $b$ are set to maximise power generation. The figures themselves vary in terms of $R_{B A}$, where Figures $8-10$ are for $R_{B A}=9.4,13.7$, and $23.5 \mathrm{~m}$, respectively, and these sizes are indicative of BAs with mass ratios less than, equal to, and greater than the spar's mass.

The RAO plots show that, for each BA, the mechanical coupling produces a spike in the spar's surge at approximately the same frequency as the peak wave frequency $\left(f_{p}=0.083 \mathrm{~Hz}\right)$. This indicates that the mechanical coupling is being tuned to amplify the surge motion of the spar. This peak in surge increases with $R_{B A}$, and this is presumably because the more massive BA can force more surge motion. The coupling also introduces a spike in the spar's pitch RAO around the peak wave period. As the mechanical coupling creates no direct pitch force (in this arrangement the spring and damper connect through the spar's CoM), this is the result of the inherent coupling between the spar's surge and pitch motion. Alongside the spike in the spar's surge RAO, there is also a spike in the 
BA's surge RAO around $f_{p}$ for the $R_{B A}=9.4$ and $13.71 \mathrm{~m}$ cases. This suggests that the power is being captured by amplifying the relative surge motion between the two bodies for these radii. For the $R_{B A}=23.5 \mathrm{~m}$ case there is no such spike in the BAs surge, and this is presumably a result of the BA being too massive for the spar to influence its motion. In addition to this, the plots give similar results for the heave RAOs (although the spike in the heave RAO occurs at approximately half the peak wave frequency for the $R_{B A}=9.4 \mathrm{~m}$ case).
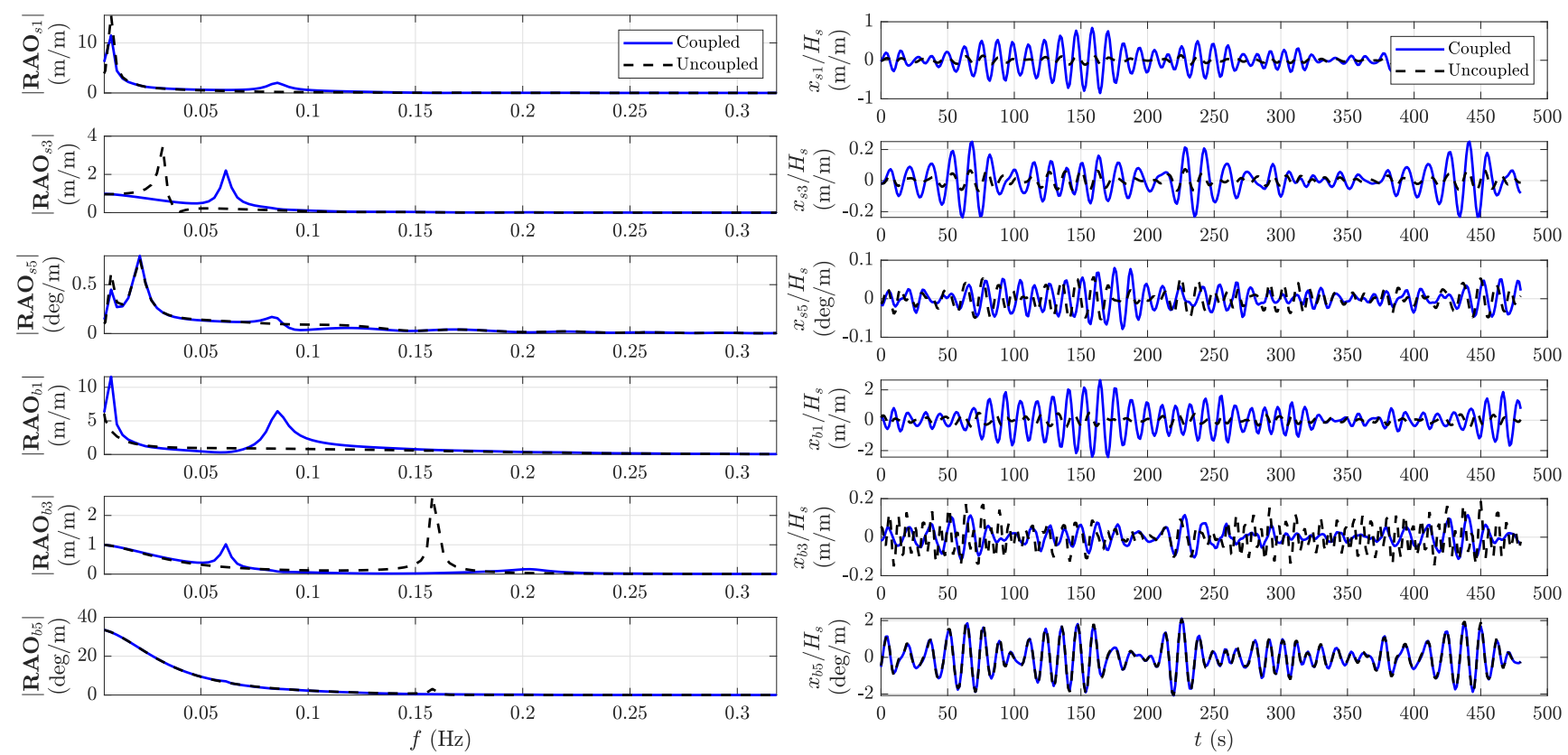

Figure 8. (Left): RAOs of spar and BA before and after coupling. (Right): Motion time series before and after coupling. Both plots are for $R_{B A}=9.4 \mathrm{~m}, D_{B A} / R_{B A}=1.00, T_{p}=12 \mathrm{~s}$, and $\Delta x=50 \mathrm{~m}$.
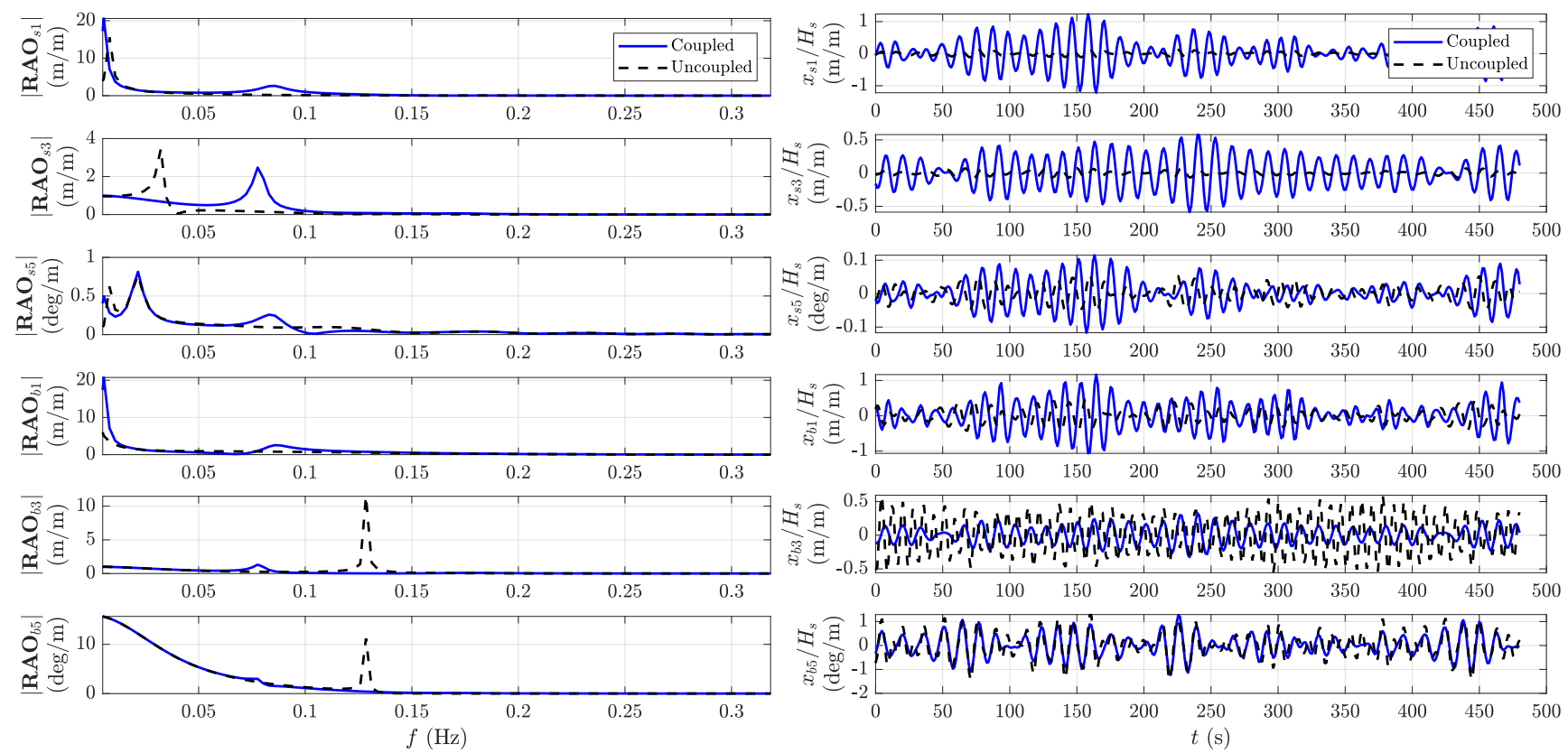

Figure 9. As in Figure 8 but with $R_{B A}=13.71 \mathrm{~m}$ (i.e., with $m_{B A}=m_{\text {spar }}$ ). 

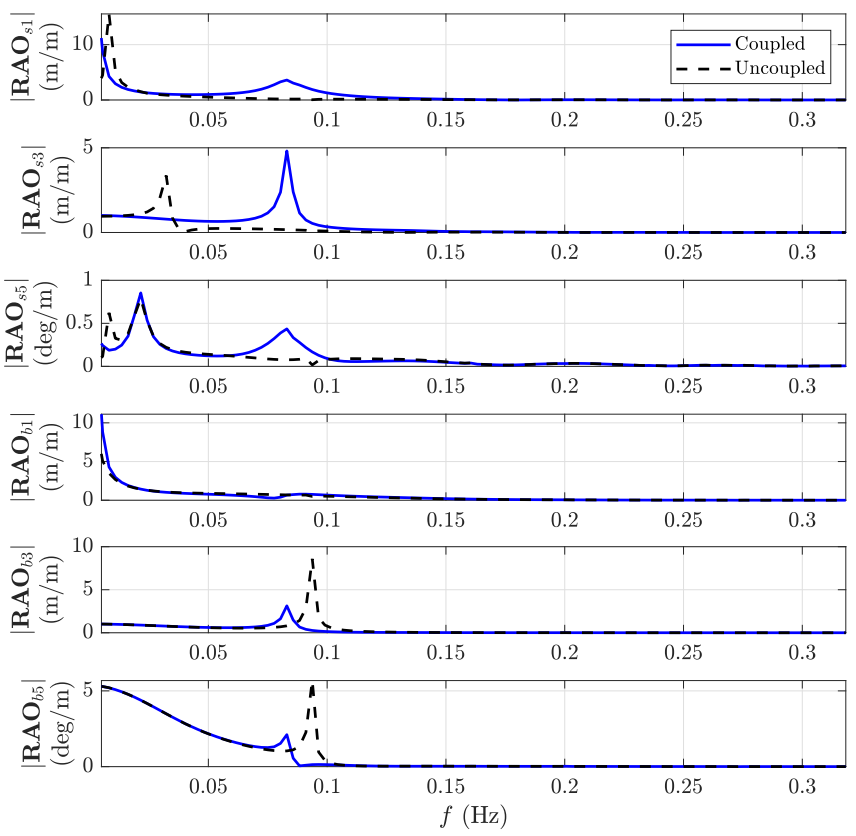
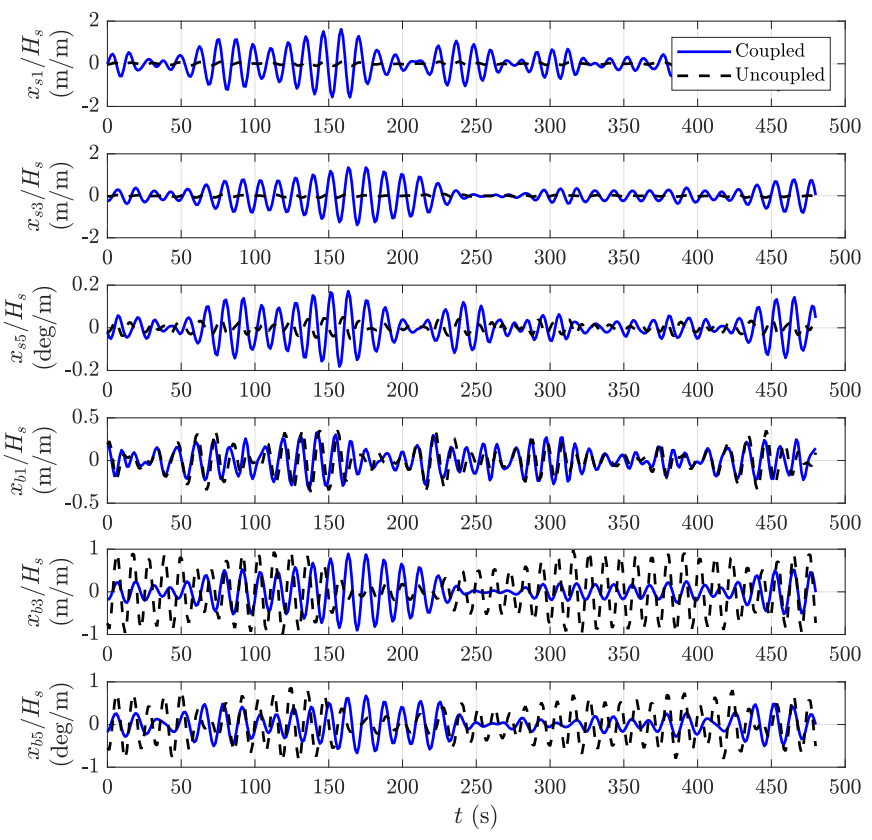

Figure 10. As in Figure 8 but with $R_{B A}=23.5 \mathrm{~m}$.

The motion plots show how these changes in the RAO alter the bodies motion. For all $R_{B A}$ the motion of the spar is amplified, and this is particularly pronounced with respect to surge. They show that there is an undesirable amplification in the spar's pitch motion, where, for example, the $R_{B A}=13.71 \mathrm{~m}$ result gives approximately double the maximum amount of pitch. The coupling also tends to amplify the motion of the BA with respect to all degrees of freedom. However, the amplifications are not as pronounced for the larger $R_{B A}$ cases and, again, this is presumably due to the BA becoming much more massive than the spar in these cases. An interesting corollary of these motion results is that, even though the BA is absorbing incident wave energy, it consistently increases the wave induced motion of the spar (rather than dampening it) when the power generation system is optimised to maximise power production.

The mode shapes and corresponding natural frequencies of the coupled system can be evaluated by taking the eigenvalues and eigenvectors of the matrix $\left(M+A\left(\omega_{p}\right)\right)\left(K_{M}+\right.$ $\left.K_{C}+K_{H}\right)^{-1}$, where the eigenvectors give the modal shape and the square root of the eigenvalues give the corresponding natural frequencies. Figure 11 shows these natural frequencies before and after coupling (left), as well as the corresponding mode shapes (right) as a function of the mass ratio between BA and spar. Note that these plots are for the case when $D_{B A} / R_{B A}=1, \Delta x=50 \mathrm{~m}$, and $L_{k}=L_{b}=78 \mathrm{~m}$, but are indicative of all results.

The plots on the left show that when the coupling is introduced, it primarily tunes the first and fourth mode's frequency towards the peak wave period (i.e., the period of the waves with the most energy). The plots of the modes' shape show that the first mode corresponds to the BA and spar surging out of phase, and the fourth mode corresponds to the bodies heaving in phase. With respect to the mass ratio, they also show that for $m_{B A} \ll m_{\text {spar }}$, the coupling system creates this resonance such that the BA's surge and heave is excited with relatively little effect on the spar, that the opposite occurs for $m_{B A} \gg m_{\text {spar }}$, and that for $m_{B A}=m_{\text {spar }}$ seems to excite the surge/heave of the BA and spar equally. Such results mimic the coupling effects that are observed in the motion time series in Figures 8-10, and indicate that the primary way in which power is being generated is from an out of phase surge-surge motion coupling between bodies. 

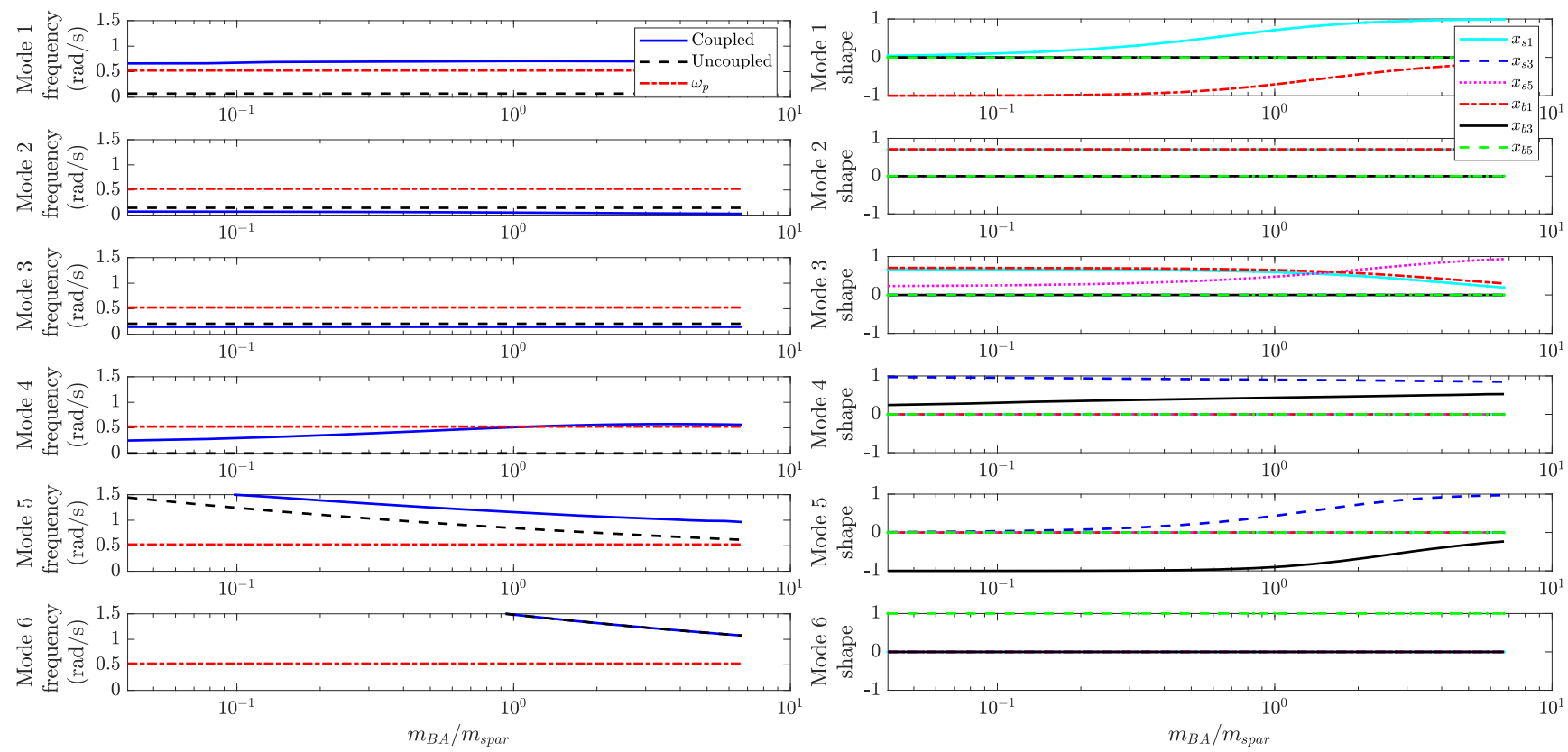

Figure 11. Modal frequency (left) and modal shape (right) as a function of $m_{B A} / m_{\text {spar }}$ for $D_{B A} / R_{B A}=1.00, \Delta x=50 \mathrm{~m}$, and $L_{k}=L_{b}=78 \mathrm{~m}$.

\subsection{Viscous Drag}

Up to this point, the model has not included the effects of viscous drag. This was to have a more computationally efficient model that is suitable to the wide range of independent variables tested and to permit more easy to interpret model evaluations (as without drag, the motion results are proportional to $H_{s}$ and power results proportional to $H_{s}^{2}$ ). Nonetheless, it has been shown that, for some wave energy applications, viscous drag is appreciable [22]. To test whether it is appropriate to neglect viscous drag for these bodies, tests were run using the same $b, k, L_{k}, L_{b}$ values that give the optimal power generation for the $D_{B A} / R_{B A}=1.00$ and $\Delta x=50 \mathrm{~m}$ cases. This viscous drag modelling was conducted using linearisation method of [24,25], (which is elaborated on in Chapter 3 of [22]). Consistent with the recommendations of [15], a sensitivity study was conducted to determine which drag coefficients were/were not necessary to include in the model. By running the viscous drag model multiple times for waves with $H_{s}=4 \mathrm{~m}$ and individually setting the drag coefficient corresponding to each degree of freedom to the significantly exaggerated value of 2, it was found that only the drag coefficients that would effect power generation by more than $1 \%$ were the drag coefficient corresponding to the surge of the spar and the drag coefficient corresponding to the surge of the BA. Therefore, only the drag coefficients for the spar and BA are included in this analysis, and these are taken using the experimentally determined coefficients outlined in [36-38] under the approximation that the spar and BA are cylindrical.

The relative difference between power generation for the inclusion/exclusion of viscous drag forcing as a function of $R_{B A}$ is shown in Figure 12, where individual panels vary in terms of $T_{p}$ and the curves in terms of $H_{s}$. It shows that for $H_{s} \leq 2$, the inclusion of viscous drag produces a change in power of less than $5 \%$ for $R_{B A} \geq 10.6$. However, for lower radii, viscous drag forces significantly reduce power generation. Viscous drag also appears to have a stronger effect on the higher radii power production for $H_{S} \geq 3$. Nonetheless, for the radius that this work advocates, which is $R_{B A}=13.7$, the effect of viscous drag only reduces power production by more than $10 \%$ for the $H_{s}=4 \mathrm{~m}$ case. 

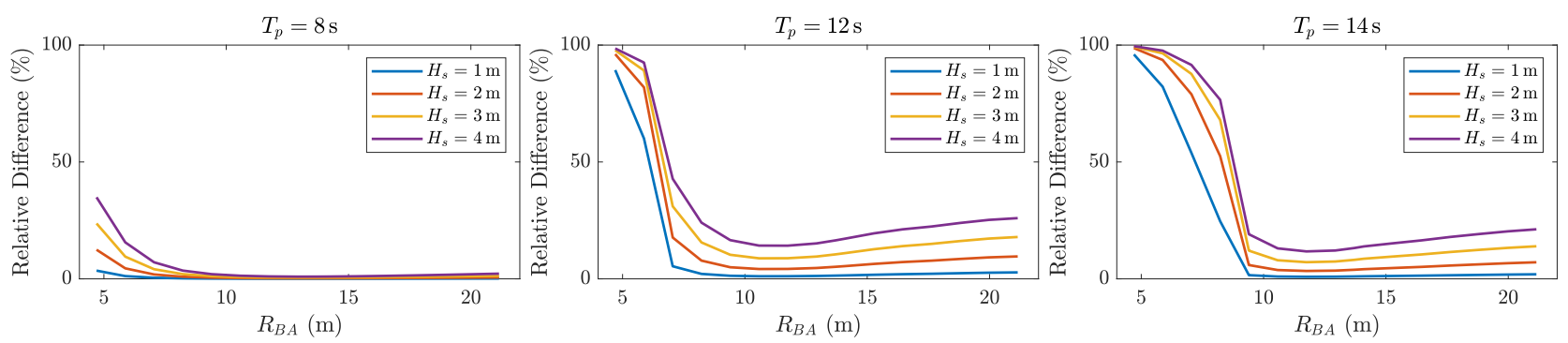

Figure 12. Percentage difference between wave power generated for model with and without viscous drag as a function of $R_{B A}$. Individual plots vary in terms of $T_{p}$ (as per the titles) and curves display varied $H_{S}$ (as per the legend). Results are taken under conditions with $D_{B A} / R_{B A}=1.00, \Delta x=50 \mathrm{~m}$, and $L_{k}=L_{b}=78 \mathrm{~m}$.

\section{Discussion}

\subsection{Summary of Results}

The potential for combining a point absorber type WEC to a spar type floating $5 \mathrm{MW}$ floating offshore wind turbine has been investigated. The spar has been modelled using the definitions of the NREL OC3 wind platform [9]. The point absorber has been modelled as a cylindrical BA. Rather than considering a specific PTO arrangement, a generalised spring and damper system has been used to model the spar-BA PTO coupling.

The results show that the optimal size (with respect to maximising wave power generation) for the $\mathrm{BA}$ is one where its mass is at least 5 times greater than the mass of the spar. However, a BA this size is most likely impractical and creates significant detrimental amplifications to the spar's surge and pitch. Under the more physically realistic constraint that the BA have equal or less mass than the spar, the optimal BA size appears to be that where $m_{B A}=m_{\text {spar }}, R_{B A}=13.7 \mathrm{~m}$, and $D_{B A}=13.7 \mathrm{~m}$. The power production of such a system varies, but results suggest that for a significant wave height of $2 \mathrm{~m}$ the power generated generally lies between 0.3 to $0.5 \mathrm{MW}$, and the potential for generation larger than $1 \mathrm{MW}$ exists for waves with a significant wave height of $3 \mathrm{~m}$ or above. It has been demonstrated that to achieve this power, the ideal mechanical coupling links the CoM of the spar to the CoM of the BA; such coupling is optimal when its stiffness and damping tunes the mode corresponding to the out of phase surge motions of the BA and spar near to the peak wave frequency. It has also been shown that viscous drag has the potential to significantly effect the power production of small and high radius BA systems. However, for the optimal BA size (the case where $R_{B A}=13.7 \mathrm{~m}$ and $D_{B A}=13.7 \mathrm{~m}$ ), it has been shown that viscous drag generally reduces power production by less than $10 \%$, which supports the modelling assumption that it is negligible for this study.

The results also indicate that a number of technical challenges might arise in trying to implement a coupled spar-BA system. For instance, it has been shown that significantly more power is generated when the mechanical coupling point on the spar is at its CoM (a location well below the SWL), and such a connection location will present significant design challenges when compared to a more convenient connection point such as that on the SWL. Furthermore, it has been shown that the presence of the BA magnifies rather than reduces the motion of the spar, and this magnification becomes more pronounced for the larger BAs that can produce more significant amounts of power.

These results contrast well with the more specific design focused studies of hybrid wind and WEC systems in the literature. The conclusions, with respect to the power generated by the WEC, support the findings of studies such as $[17,20,21,39,40]$, which show that there is the potential to produce a promising amount of power from a hybrid system, whether that be with a single or multiple WECs. The relative capture width results also give support to the design ideas of $[17,21,40]$, which use multiple smaller WECs to generate power rather than fewer larger ones. However, with respect to net power generation, this work shows that the optimal power per BA size requires much larger BAs than considered in prior works. In contrast to other works, such as [21,40], it was found that for the optimal amount of power to be generated through the WEC system, the result 
is an appreciable amplification of spar motions rather than suppression of them. This is not to say that the WEC system cannot suppress spar motions as found for other hybrid wind and WEC models, but rather implies that to both suppress spar motions and generate power, compromises need to be made; a similar finding has been made in the analysis of the specific hybrid platform proposed in [17].

\subsection{Limitations and Future Work}

In order to study this problem and its wide space of independent parameters, this work has used an idealised linear two-dimensional model. Although this simplification is necessary for this work, it does have its resulting limitations. Firstly, it implies that the potential consequence of having the wind direction offset from the wave direction has not been studied. In the confines of this model, an offset wind direction would mean an overall reduction in the entries of the wind damping matrix $\left(B_{W}\right)$. However, in a real-world system, an offset means that the spar would experience oscillations in both the roll and pitch degrees of freedom. This could potentially introduce significant precession, particularly when the gyroscopic coupling between rotation of the rotors and the roll and pitch of the spar are considered. Apt modelling of this will require a nonlinear model, which is why it has not been included in this work. Secondly, on a similar point, it has been assumed that the CoM of the spar and BA lie along the direction of the incident waves. In reality, the angle between the bodies and the wave direction will almost always be offset due to the drift forces of wind, waves, and currents. Therefore, to overcome this limitation, it would be useful to continue this study with an analysis of offset wind, wave, and body alignment angles, which would require three-dimensional modelling. Thirdly, in an effort to benchmark the performance of a hybrid wind and WEC system, the PTO system has been abstracted and limited to a generic spring and damper system. In the real world, there will inevitably be technical challenges in designing such a system such that future work can be adapted around what might be the most physically realisable. Finally, the model in this study is limited by its overall linearity with respect to wave amplitude. Certain physical phenomena (such as the nonlinearity in PTO forcing due to changing connection angles) have, therefore, been simplified within this framework. Such simplifications have been necessary within the scope of the independent parameters investigated; however, it again introduces the prospect that it would be useful to expand upon these results by considering more nonlinear models, such as CFD or the Cummins equations based methodologies [22].

In addition to addressing these limitations, there appears to be a number of ways to further the investigation of the potential for coupling a spar type wind turbine to a point absorber. As the BA is producing undesirable motion amplifications in the spar, multi-objective optimisation with respect to the spring and damping coefficients might be necessary to prevent these undesirable motion amplifications. Further, because the single BA considered in this study is still unable to produce power akin to that of the $5 \mathrm{MW}$ turbine, it may be useful to consider the power that could be generated from using multiple BAs within this abstracted PTO framework. Such investigations might be particularly useful, because this work has found that the RCW is larger for smaller BA sizes and the specific designs of $[21,40]$ and others ask for smaller multiple BAs. Finally, while this work has provided performance benchmarks given various wave conditions, further work should be conducted to evaluate how a BA might perform in real-world sites by averaging across the observed wave conditions there.

Author Contributions: All authors (D.M.S., N.S., B.D., and B.C.) contributed equally. All authors have read and agreed to the published version of the manuscript.

Funding: This work is funded by the Australia-China JRC of Offshore Wind and Wave Energy Harnessing (GA55843).

Institutional Review Board Statement: Not applicable.

Informed Consent Statement: Not applicable. 
Data Availability Statement: The code and data used for and presented in this study are available on request from the corresponding authors.

Conflicts of Interest: The authors declare no conflict of interest.

\section{Abbreviations}

The following abbreviations are used in this manuscript:

$\begin{array}{ll}\text { BA } & \text { Buoyant actuator } \\ \text { BEM } & \text { Blade element momentum } \\ \text { CFD } & \text { Computational fluid dynamics } \\ \text { CoM } & \text { Centre of mass } \\ \text { JONSWAP } & \text { Joint North Sea Wave Project } \\ \text { LCOE } & \text { Levelised cost of energy } \\ \text { NREL } & \text { National Renewable Energy Laboratory } \\ \text { OC3 } & \text { Offshore Code Comparison Collaboration } \\ \text { RAO } & \text { Response amplitude operator } \\ \text { RCW } & \text { Relative capture width } \\ \text { SWL } & \text { Still water line } \\ \text { WEC } & \text { Wave energy converter }\end{array}$

\section{Symbols}

The following mathematical symbols are used in this manuscript:

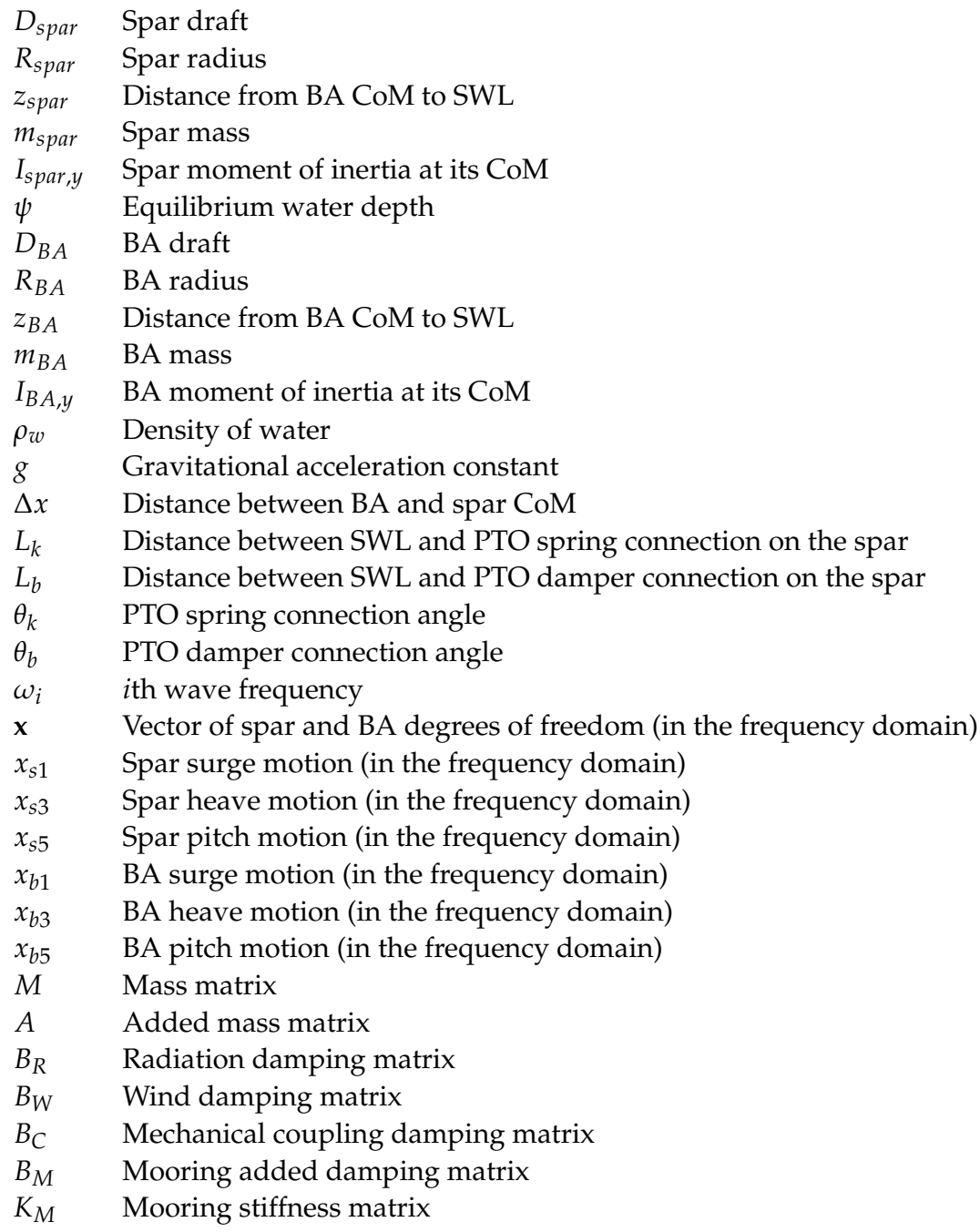




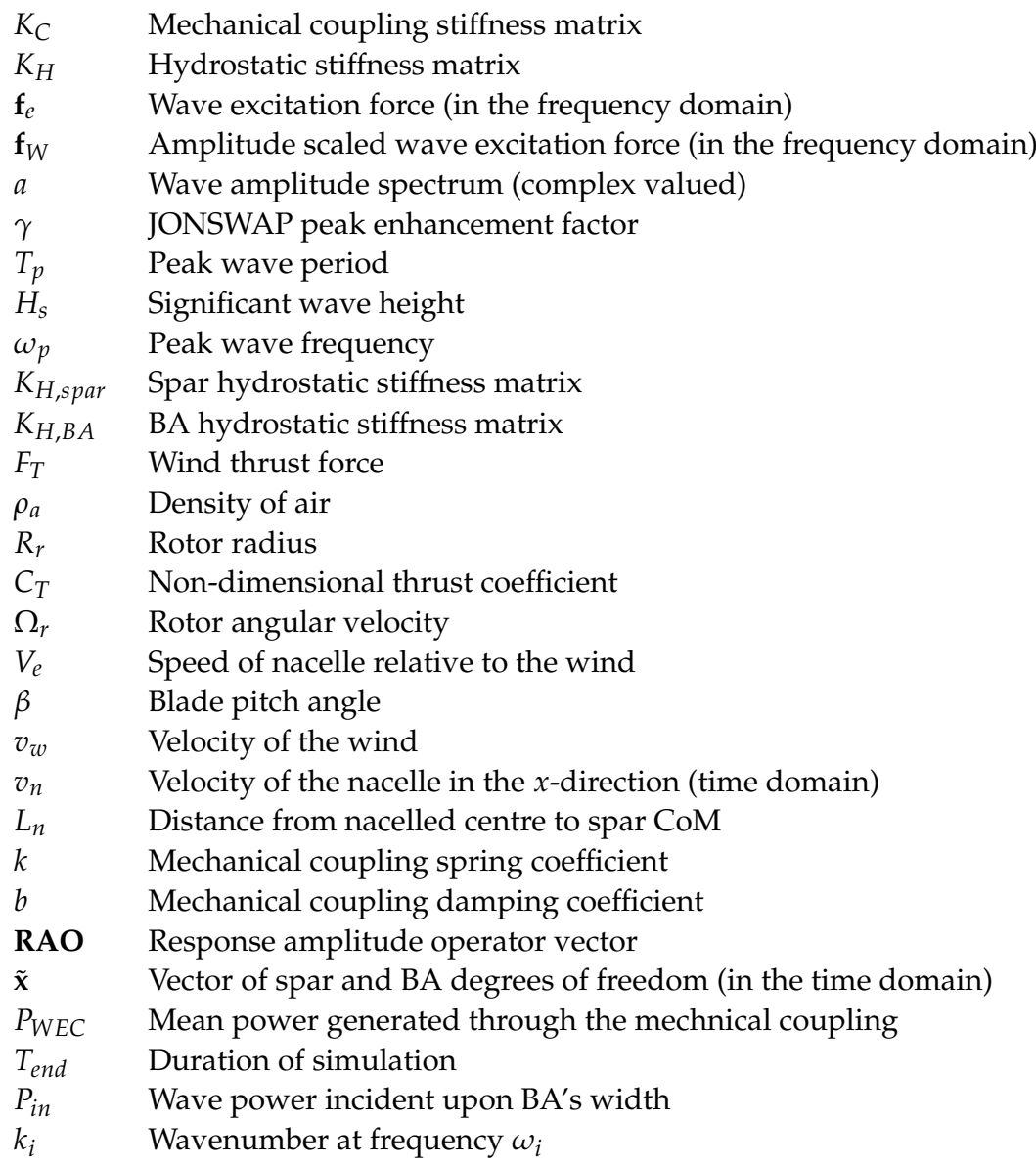

\section{Appendix A. JONSWAP Spectrum}

The JONSWAP spectrum is defined in terms of the power spectral density function $[29,41]$

$$
S(\omega)=\frac{\alpha g^{2}}{\omega^{5}} \exp \left[-\frac{5}{4}\left(\frac{\omega_{p}}{\omega}\right)^{4}\right] \gamma^{r},
$$

where,

$$
\begin{aligned}
& r=\exp \left[-\frac{\left(\omega-\omega_{p}\right)^{2}}{2 \sigma^{2} \omega_{p}^{2}}\right], \quad \alpha=5.058(1-0.287 \ln (\gamma))\left(\frac{H_{s}}{T_{p}^{2}}\right)^{2}, \quad T_{p}=\frac{2 \pi}{\omega_{p}}, \quad \text { and } \\
& \sigma= \begin{cases}0.07, & \text { if } \omega \leq \omega_{p} \\
0.09, & \text { otherwise. }\end{cases}
\end{aligned}
$$

By definition, the relationship between the power spectral density function and the (continuous) amplitude spectral density function, $\hat{a}(\omega)$, is $S(\omega)=0.5|\hat{a}(\omega)|^{2} \mathrm{~d} \omega$. Therefore, when evaluated numerically, this allows the magnitude of the discrete amplitude spectrum, $a\left(\omega_{i}\right)$, to be emulated as

$$
\left|a\left(\omega_{i}\right)\right|=\sqrt{2 S\left(\omega_{i}\right) \Delta \omega},
$$

where $\Delta \omega=\omega_{i+1}-\omega_{i}$.

With respect to the phase of the discrete amplitude spectrum, it is well established that because ocean waves are dispersive and generated through turbulent interactions with the air, there is no correlation between the phase of the amplitude spectrum at any frequency [41]. In simpler terms, this means the phase difference between any two 
components of the amplitude spectrum is completely random, and therefore the phase of the spectrum is given by

$$
\arg \left(a\left(\omega_{i}\right)\right) \sim U(-\pi, \pi)
$$

for all $\omega_{i}$, where $U(-\pi, \pi)$ is the uniform distribution between $-\pi$ and $\pi$; i.e., the phase of $\arg \left(a\left(\omega_{i}\right)\right)$ is generated as a random value between $-\pi$ and $\pi$. Note that for fair comparison between tests, each test with a given $T_{p}$ and $H_{s}$ uses the same values of $\arg \left(a\left(\omega_{i}\right)\right)$ between runs.

\section{References}

1. Pérez-Collazo, C.; Greaves, D.; Iglesias, G. A review of combined wave and offshore wind energy. Renew. Sustain. Energy Rev. 2015, 42, 141-153. [CrossRef]

2. Azzellino, A.; Lanfredi, C.; Riefolo, L.; De Santis, V.; Contestabile, P.; Vicinanza, D. Combined exploitation of offshore wind and wave energy in the Italian seas: A spatial planning approach. Front. Energy Res. 2019, 7, 42. [CrossRef]

3. Anuta, H.; Ralon, P.; Taylor, M. Renewable Power Generation Costs in 2018; Technical Report; IRENA: Abu Dhabi, United Arab Emirates, 2019.

4. Rusu, E.; Onea, F. A review of the technologies for wave energy extraction. Clean Energy 2018, 2, 10-19. [CrossRef]

5. Sun, X.; Huang, D.; Wu, G. The current state of offshore wind energy technology development. Energy 2012, 41, $298-312$. [CrossRef]

6. Thiagarajan, K.; Dagher, H. A review of floating platform concepts for offshore wind energy generation. J. Offshore Mech. Arct. Eng. 2014, 136, 020903.

7. Bachynski, E.E.; Moan, T. Design considerations for tension leg platform wind turbines. Mar. Struct. 2012, 29, 89-114. [CrossRef]

8. Liu, Y.; Li, S.; Yi, Q.; Chen, D. Developments in semi-submersible floating foundations supporting wind turbines: A comprehensive review. Renew. Sustain. Energy Rev. 2016, 60, 433-449. [CrossRef]

9. Jonkman, J.; Butterfield, S.; Musial, W.; Scott, G. Definition of a 5-MW Reference wind Turbine for Offshore System Development; Technical Report; National Renewable Energy Laboratory: Golden, CO, USA, 2009.

10. Amano, R.S. Review of wind turbine research in 21st century. J. Energy Resour. Technol. 2017, 139, 050801. [CrossRef]

11. Drew, B.; Plummer, A.R.; Sahinkaya, M.N. A review of wave energy converter technology. Proc. Inst. Mech. Eng. Part A J. Power Energy 2009, 223, 887-902. [CrossRef]

12. Falnes, J. A review of wave-energy extraction. Mar. Struct. 2007, 20, 185-201. [CrossRef]

13. Antonio, F. Wave energy utilization: A review of the technologies. Renew. Sustain. Energy Rev. 2010, 14, 899-918.

14. Sheng, W. Wave energy conversion and hydrodynamics modelling technologies: A review. Renew. Sustain. Energy Rev. 2019, 109, 482-498. [CrossRef]

15. Babarit, A.; Hals, J.; Muliawan, M.J.; Kurniawan, A.; Moan, T.; Krokstad, J. Numerical benchmarking study of a selection of wave energy converters. Renew. Energy 2012, 41, 44-63.

16. Pelagic Power. Available online: http:/ / www.pelagicpower.no (accessed on 19 August 2021).

17. Si, Y.; Chen, Z.; Zeng, W.; Sun, J.; Zhang, D.; Ma, X.; Qian, P. The influence of power-take-off control on the dynamic response and power output of combined semi-submersible floating wind turbine and point-absorber wave energy converters. Ocean. Eng. 2021, 227, 108835. [CrossRef]

18. Karimirad, M.; Koushan, K. WindWEC: Combining wind and wave energy inspired by hywind and wavestar. In Proceedings of the 2016 IEEE International Conference on Renewable Energy Research and Applications, Birmingham, UK, 20-23 November 2016; pp. 96-101.

19. Sismani, G.; Loukogeorgaki, E. Frequency-based investigation of a floating wave energy converter system with multiple flaps. Appl. Math. Model. 2020, 84, 522-535. [CrossRef]

20. Borg, M.; Collu, M.; Brennan, F.P. Use of a wave energy converter as a motion suppression device for floating wind turbines. Energy Procedia 2013, 35, 223-233.

21. Hu, J.; Zhou, B.; Vogel, C.; Liu, P.; Willden, R.; Sun, K.; Zang, J.; Geng, J.; Jin, P.; Cui, L.; et al. Optimal design and performance analysis of a hybrid system combing a floating wind platform and wave energy converters. Appl. Energy 2020, 269, 114998. [CrossRef]

22. Folley, M. Numerical Modelling of Wave Energy Converters: State-of-the-Art Techniques for Single Devices and Arrays; Academic Press: Cambridge, MA, USA, 2016.

23. Bianchi, F.D.; De Battista, H.; Mantz, R.J. Wind Turbine Control Systems: Principles, Modelling and Gain Scheduling Design; Springer Science \& Business Media: Berlin/Heidelberg, Germany, 2006.

24. Borgman, L.E. Random hydrodynamic forces on objects. Ann. Math. Stat. 1967, 38, 37-51.

25. Borgman, L.E. Statistical models for ocean waves and wave forces. In Advances in Hydroscience; Elsevier: Amsterdam, The Netherlands, 1972; Volume 8, pp. 139-181.

26. Babarit, A.; Delhommeau, G. Theoretical and numerical aspects of the open source BEM solver NEMOH. In Proceedings of the 11th European Wave and Tidal Energy Conference, Nantes, France, 6-11 September 2015. 
27. Zhou, Y.; Xiao, Q.; Liu, Y.; Incecik, A.; Peyrard, C.; Li, S.; Pan, G. Numerical modelling of dynamic responses of a floating offshore wind turbine subject to focused waves. Energies 2019, 12, 3482. [CrossRef]

28. Penalba, M.; Kelly, T.; Ringwood, J. Using NEMOH for modelling wave energy converters: A comparative study with WAMIT. In Proceedings of the 12th European Wave and Tidal Energy Conference, College Cork, Ireland, 27 August-1 September 2017.

29. Hasselmann, K.; Barnett, T.; Bouws, E.; Carlson, H.; Cartwright, D.; Enke, K.; Ewing, J.; Gienapp, H.; Hasselmann, D.; Kruseman, P.; et al. Measurements of wind-wave growth and swell decay during the Joint North Sea Wave Project (JONSWAP). Ergänzungsheft zur Deutschen Hydrographischen Zeitschrift 1973, 12, 8-12.

30. Jiang, S.; Gou, Y.; Teng, B.; Ning, D. Analytical solution of a wave diffraction problem on a submerged cylinder. J. Eng. Mech. 2014, 140, 225-232.

31. Jonkman, J. Definition of the Floating System for Phase IV of OC3; Technical Report; National Renewable Energy Laboratory: Golden, CO, USA, 2010.

32. Jonkman, J.M. Dynamics Modeling and Loads Analysis of an Offshore Floating Wind Turbine; Technical Report; National Renewable Energy Laboratory: Golden, CO, USA, 2007.

33. Da Silva, L.S.; Cazzolato, B.S.; Sergiienko, N.Y.; Ding, B. Efficient estimation of the nonlinear aerodynamic loads of floating offshore wind turbines under random waves and wind in frequency domain. J. Ocean. Eng. Mar. Energy 2021, 7, 287-303. [CrossRef]

34. Mei, C.C.; Stiassnie, M.; Yue, D.K.P. Theory and Applications of Ocean Surface Waves; World Scientific: Singapore, 2005 ; Volume 23.

35. Sergiienko, N.Y.; Cazzolato, B.S.; Ding, B.; Arjomandi, M. Three-tether axisymmetric wave energy converter: Estimation of energy delivery. In Proceedings of the 3rd Asian Wave and Tidal Energy Conference, Singapore, 25-27 October 2016; pp. 23-25.

36. Sarpkaya, T. Forces on cylinders and spheres in a sinusoidally oscillating fluid. ASME J. Appl. Mech. 1975, 42, 32-37.

37. Singh, S. Forces on Bodies in an Oscillatory Flow. Ph.D. Thesis, Imperial College London, London, UK, 1979.

38. Graham, J. The forces on sharp-edged cylinders in oscillatory flow at low Keulegan-Carpenter numbers. J. Fluid Mech. 1980, 97, 331-346. [CrossRef]

39. Lee, H.; Poguluri, S.K.; Bae, Y.H. Performance analysis of multiple wave energy converters placed on a floating platform in the frequency domain. Energies 2018, 11, 406. [CrossRef]

40. Ghafari, H.R.; Ghassemi, H.; He, G. Numerical study of the Wavestar wave energy converter with multi-point-absorber around DeepCwind semisubmersible floating platform. Ocean. Eng. 2021, 232, 109177. [CrossRef]

41. Holthuijsen, L.H. Waves in Oceanic and Coastal Waters; Cambridge University Press: Cambridge, UK, 2010. 